\title{
Maestros y educadores españoles en el siglo XVIII
}

\author{
Olegario Negrín Fajardo \\ Departamento de Historia de la Educación \\ Universidad Nacional de Educación a Distancia
}

Resumen:

En el siglo XVIII existieron diversos profesionales de la enseñanza para los distintos niveles educativos, que van desde el maestro de enseñanza de primeras letras al profesor de universidad, pasando por los leccionistas, los pasantes, los preceptores, los ayos y los profesores de la etapa posterior a la enseñanza primaria y previa a la universidad que hoy llamamos secundaria, sin olvidar a los maestros de enseñanzas artísticas y profesionales, a los educadores de hospicios y a las maestras-amigas. Pero este artículo está referido sólo a los maestros y educadores que se ocupaban de la enseñanza del pueblo llano, lo que con frecuencia se denomina educación popular, y que se puede aplicar a la mayoría de la población española del siglo XVIII. Consideramos que bajo este epígrafe de maestros y educadores españoles del siglo XVIII caben los que entonces se denominaban maestros de primeras letras y maestros de artes y oficios, seglares y religiosos, aunque también señalaremos algunos ejemplos, para este primer nivel de la enseñanza, en el ámbito de la educación doméstica de los grupos aristocráticos y burgueses.

Palabras claves:

Educación popular. Primeras letras. Hermandad de San Casiano. Escuelas De los Reales Sitios.

CES.XVIII, núm. 15 (2005), págs. 117-157. 


\section{Introducción}

El número de investigaciones elaboradas y publicadas acerca de la educación en el siglo XVIII, desde diversas perspectivas, es elevado, pero siguen existiendo temas, como el de los tipos y perfiles de maestros y profesores, que no están suficientemente tratados seguramente porque no han sido interpretados con la metodología y la creatividad necesarias. Así, cuando hemos tenido que volver a repasar las principales publicaciones en torno a la educación ilustrada española para destacar el perfil del maestro dieciochista, lo primero que hemos observado es la indefinición que existe a este respecto; de hecho, unos autores hacen una clasificación que deja fuera muchos datos educativos comprobados; otras investigaciones resultan en parte contradictorias y, en algunas ocasiones, se confunden los diferentes tipos de educadores que existieron en aquella época o dejan al margen a algunos de ellos.

Porque, en realidad, existieron diversos y variados profesionales de la enseñanza en el siglo XVIII para cada nivel educativo, que van desde el maestro de enseñanza de primeras letras al profesor de universidad, pasando por los leccionistas, los pasantes, los preceptores, los ayos y los profesores de la etapa posterior a la enseñanza primaria y previa a la universidad que hoy llamamos secundaria, sin olvidar a los maestros de enseñanzas artísticas y profesionales y a educadores de hospicios y maestras-amigas, más bien cuidadoras de niños, por poner algunos ejemplos más. También habría que incluir a los enseñantes religiosos en los diversos niveles educativos que ofrecen unas características singulares que les distinguen de los demás.

Pero el objeto de este artículo es más concreto y está referido sólo a los maestros y educadores que se ocupaban de la enseñanza del pueblo llano, lo que con frecuencia se denomina educación popular, y que se puede aplicar a la mayoría de la población española del siglo XVIII. Consideramos que bajo este epígrafe de maestros y educadores españoles del siglo XVIII caben los que entonces se denominaban maestros de primeras letras y maestros de artes y oficios, seglares y religiosos, aunque también señalaremos algunos ejemplos, para este primer nivel de la enseñanza, en el ámbito de la educación doméstica de los grupos aristocráticos y burgueses ${ }^{1}$.

1 Este artículo está basado en una ponencia preparada para el Curso de Verano de la Universidad de Oviedo, «Maneras de vivir en el siglo XVIII», dirigido por los profesores Álvaro Ruiz de la Peña e Inmaculada Urzainqui, en el curso académico 2002-2003. Nuestra participación consistió en exponer los tipos de maestros en el siglo XVIII, a partir de lo que nos es posible saber, teniendo en cuenta la bibliografía y la documentación de la que disponemos y la amplia serie de investigaciones ya realizadas acerca de la centuria ilustrada y, en particular, la educación y la pedagogía dieciochista españolas. Desde aquí vuelvo a reiterar mi agradecimiento 
Dicho de otra manera, hay que explicar desde el principio que existían dos tipos de enseñanzas diferentes; una, la ejercida por el clero, a través de sus órdenes y congregaciones religiosas, y, otra, la que llevaban a cabo los maestros seglares, agremiados o no; por otra parte, existía una enseñanza para los niños del pueblo, la mayoría de la población, que estaba a cargo de los maestros seglares y de los maestros de los escolapios o Escuelas Pías; pero también se puede, y se debe, establecer otra clasificación que distingue la enseñanza popular, ejercida por los maestros seglares y religiosos de primeras letras, de la enseñanza de la aristocracia y los grupos burgueses en formación, ejercida a través de preceptores y ayos en un sistema de educación privada que llegó a tener una significativa importancia. Finalmente, otra clasificación válida, y en la práctica la más singular, es la que diferencia a los maestros del antiguo régimen de los Austrias y primeros Borbones de los maestros plenamente ilustrados, que van apareciendo en el último tercio del siglo XVIII, en los ámbitos de la educación profesional y de la educación de las primeras letras.

Teniendo en cuenta tales clasificaciones y la realidad del magisterio en el siglo ilustrado, empezaremos por ocuparnos en primer lugar del que, durante la primera mitad del siglo XVIII, fue el tipo más común de maestro, al que se puede denominar «maestro del Antiguo Régimen». Se trata del maestro gremial de la Hermandad de San Casiano; bien entendido que dentro del apartado contemplamos a los maestros de las ciudades, a los maestros rurales y a las maestras.

Con Carlos III en el poder y el pensamiento ilustrado en su máximo apogeo se modernizará la Hermandad de San Casiano y pronto aparecerá el Colegio Académico de Primeras Letras, que es, junto con la Real Academia de Primera Educación, la verdadera institución ilustrada de formación de maestros. Con estos cambios aparece el maestro ilustrado, con una formación y un talante distinto a lo que se conocía hasta esa fecha.

Analizados los dos tipos principales de maestros españoles del siglo XVIII, estudiaremos con cierto detenimiento los planteamientos teóricos alternativos, del maestro ilustrado necesario, que diseñó para Canarias Viera y Clavijo ${ }^{2}$, y el

a los citados profesores por haber tenido en cuenta, dentro de las maneras de vivir del siglo XVIII, la singular de «maestros y profesores» y haberme encargado de elaborar un tema tan apasionante como ciertamente múltiple y complejo. Ahora se da a conocer este artículo transformando por completo aquel trabajo inicial e incorporando todo el aparato crítico necesario.

2 Aunque existe una amplia bibliografía en torno a Viera y Clavijo, su perspectiva educativa es menos conocida. Véase a este respecto: Olegario NEgrín, «José de Viera y Clavijo», en Olegario NEgrín (dir.), Historia de la educación en España. Autores, textos y documentos, Madrid, UNED, 2004, págs. 161-168. También del mismo autor: «Un proyecto ilustrado de transformación de la realidad educativa canaria: el Síndico Personero de Viera y Clavijo», en IX Coloquio de Historia Canario-Americana, Las Palmas de Gran Canaria, Ediciones del Cabildo Insular de Gran Canaria, tomo II, 1993, págs. 919-946. «Retablo de educadores canarios contemporáneos: de Viera y Clavijo a Champsaur Sicilia», en Anuario de Estudios Atlánticos, Madrid-Las Palmas, 1982, 
modelo de maestro ilustrado más radical o, si se quiere, más auténtico, que es el que defiende Cabarrús en sus Cartas ${ }^{3}$.

A continuación nos ocupamos de explicar la especial situación de las maestras, cuya formación estaba aún más abandonada que la del maestro; señalaremos los diferentes tipos de maestras que van surgiendo al socaire de la política ilustrada, más preocupada del desarrollo económico nacional que de la educación de las niñas y muchachas.

Después de señalar los tipos de maestros seglares que se consolidaron en el siglo XVIII, llega el turno a los maestros religiosos, especialmente a los escolapios que estaban especializados en la educación de los pobres, aunque no descartaron en ninguna ocasión ocuparse de otros niveles educativos.

Finalmente, pondremos una serie de ejemplos de cómo se desarrolló la enseñanza privada de la mano de unos peculiares enseñantes, unos más preparados que otros, que se ocupaban de la formación de niños de familias con posibilidades económicas para hacer frente al coste de la enseñanza de sus hijos.

Pero, en primer lugar, para poder explicar quiénes eran los «enseñantes» de primeras letras y educación popular en el siglo XVIII español, cómo se formaban, qué proceso de selección seguían e, incluso, qué enseñaban y a quiénes, es preciso que demos algunas pinceladas acerca del contexto educativo y socioeconómico y político en el que desarrollaban su actividad o quehacer pedagógico.

\section{Ideas pedagógicas, educación e ilustración en España}

Nos parece oportuno recurrir al magnífico resumen, que no es fácil de superar por su capacidad de síntesis y de valoración de las ideas pedagógicas en el siglo XVIII, que elabora en su conocida obra Historia de la Educación y la Pedagogía 4 , Lorenzo Luzuriaga, uno de los historiadores españoles de la educación que más ha contribuido al fomento de la investigación y a la divulgación de esta disciplina y que para desgracia nuestra se vio obligado a ejercer su magisterio fuera de nuestras fronteras a partir de la guerra civil. Este autor,

n. ${ }^{\circ}$ 28, págs. 705-764. «El Síndico Personero general de Viera y Clavijo o el estado de la enseñanza tinerfeña en la segunda mitad del siglo XvIII y sus posibles reformas», en Educación e Ilustración en España, III Coloquio Nacional de Historia de la Educación, Barcelona, Universidad de Barcelona, 1984, págs. 276-284.

3 Vid. Olegario Negrín, «Francisco Cabarrús», en Olegario Negrín (dir.), op. cit., págs. 193 y ss. Puede consultarse también nuestro artículo: «La Carta II de Francisco Cabarrús, una alternativa pedagógica al sistema educativo español de finales del siglo XVIII», en Revista Ciencias de la Educación, Madrid, 1979, n. ${ }^{\circ}$ 97, págs. 47-69.

4 Lorenzo Luzuriaga, Historia de la Educación y la Pedagogía, Buenos Aires, Losada, 1973, págs. 164 y ss. 
representante español durante bastantes años en el movimiento internacional de la Escuela Nueva, expone que en el siglo ilustrado se detecta que en la teoría pedagógica, en una primera fase, predominan las ideas intelectualistas y sensorialistas, en una segunda fase lo hacen las ideas naturalistas de Rousseau, y en su último tercio, el idealismo de Pestalozzi. Sin olvidar el movimiento filantrópico de Basedow y la pedagogía política representada por La Chalotais y Condorcet. Las ideas pedagógicas citadas las resume Luzuriaga en las siguientes:

1. ' La creencia en el poder absoluto de la razón, que debe gobernar a los hombres y a los pueblos, y por lo tanto la importancia extraordinaria de la educación, encargada de dirigirla.

2. ${ }^{\text {a }}$ La aspiración a la libertad, suprimiendo todas las trabas políticas y religiosas, así como las convenciones sociales, y de aquí el individualismo en la educación.

$3 .^{a}$ El reconocimiento de la naturaleza y de las leyes naturales en el universo y la sociedad, dando lugar así al naturalismo pedagógico.

4. ${ }^{a}$ Un sentido activo, progresista, optimista de la vida, que hace de la educación un instrumento valioso.

5. ${ }^{a}$ El despertar del espíritu social, de ayuda y cooperación, que produce una nueva concepción de la educación.

6. ${ }^{a}$ La progresiva secularización de la educación, reduciendo cada vez más la influencia eclesiástica y acentuando la del Estado.

La Ilustración española también se puede caracterizar de esa manera, si bien el ritmo de implantación de las ideas pedagógicas apuntadas fue distinto al producido en otros países europeos como Francia, Inglaterra o Alemania y, además, se encontró con muchos más y muy poderosos obstáculos. Se entenderá mejor lo que decimos si nos fijamos en que mientras en Inglaterra se producía la primera revolución industrial o en Francia aparecía la Enciclopedia, y poco después se ponía en marcha una larga etapa revolucionaria que consolidaría los comienzos del Estado moderno, en España la Inquisición y los poderes conservadores controlaban la cultura y la sociedad e impedían en buena parte la aplicación de las medidas renovadoras en el ámbito de la economía, que pretendían modernizar el país y poner en marcha el sistema liberal que estaba propiciando el desarrollo de otros países europeos. La minoría ilustrada se plantea atacar, bien para cambiar bien para eliminar, los obstáculos que se oponían a la implantación de las luces que, en definitiva, estaban relacionados con la propiedad de la tierra, el desarrollo productivo, la libertad de expresión y de pensamiento, la separación 
entre la Iglesia y el Estado, la secularización de la vida social y la aplicación de las reformas que la nueva mentalidad exigía para modernizar al país.

Para ello, entre las numerosas citas posibles que se pudieran utilizar en torno a la problemática del despotismo ilustrado español, tomadas de las obras de los principales especialistas del siglo XVIII, tanto nacionales como extranjeros, sólo mencionaremos a continuación algunas bien significativas de la ilustración hispánica ${ }^{5}$, para centrar el análisis y la valoración educativa que haremos con posterioridad.

Alcázar Molina caracterizaba así el peculiar Despotismo Ilustrado que se dio en nuestro país:

Absolutismo, gobierno sin Cortes, que sólo se reunirían para jurar al nuevo monarca; protección y entusiasmo por los nuevos principios económicos y las doctrinas económicas que llegaban de Francia; sentido profundamente monárquico; regalismo y defensa de cuantas prerrogativas y derechos entienden que corresponden a la Corona; influencia de la Corte de Versalles en política y administración; y de Nápoles por el reflejo de Tanucci, siempre presente en el recuerdo de juventud del monarca, pero con tendencia a españolizar al gobierno (...); anhelo de progreso y reformas interiores en las ciudades de España y América, libertad de comercio, organización de los correos marítimos para fomentar las comunicaciones con nuestros virreinatos; creación de compañías de navegación, los llamados navíos de la Ilustración, política generosa para ayudar y favorecer a los desvalidos, huérfanos y enfermos, mejorando los hospitales y las casas de misericordia, fomento de las Sociedades Económicas de Amigos del País, que representan la difusión de la cultura (...); reconstrucción interior de España, canales de riego, pantanos, repoblación de montes, cultivos de tierras incultas, fomento de fábricas y manufacturas nacionales; fundación del Banco Nacional, con la dirección de Cabarrús; restauración de la riqueza general y política nacional, favoreciendo a todas las clases sociales, especialmente a las más necesitadas y humildes; colonización interior, repoblación de Sierra Morena (... $)^{6}$.

Según Tierno Galván, «la adormecida Ilustración española encontró la posibilidad de crecer en el avivamiento de la industria y en la formación de una incipiente clase media, cuya estabilidad y permanencia dependían de la riqueza comercial e industrial. No obstante, la mentalidad de esta clase media en conato, no era por completo la europea. La estimación y valoración del dinero y la riqueza

\footnotetext{
5 Más datos en nuestra obra: Olegario NEGRín, Educación popular en la España de la segunda mitad del siglo XVIII, Madrid, UNED, 1987, capítulo primero.

6 Pedro Aguado Bleye, Manual de Historia de España, Madrid, Espasa Calpe, 1947-1953, 3 vols., t. III, pág. 35.
} 
no encajan en el canon europeo» ${ }^{7}$. En este aspecto coincide Américo Castro cuando dice:

Algunos creen que al llegar el siglo XVIII España se incorporó a Europa, se emparejó con ella... los reflejos españoles de la Ilustración fueron tenues, y no afectaron de veras a la relación del hombre consigo mismo, con la Sociedad, con Dios y con la naturaleza... La herejía de algunos intelectuales a fin del siglo XVIII era simple eco de lo pensado fuera de España. Espontáneamente los españoles no tenían nada propio con qué reemplazar sus creencias tradicionales, en algunos casos se limitaban a reaccionar violentamente contra ellas en forma ingenua, brutal y desmandada ${ }^{8}$.

Pensadores conservadores han analizado este mismo hecho desde una perspectiva diferente. Así, por ejemplo, Menéndez Pelayo da la siguiente interpretación:

La resistencia española contra el enciclopedismo y la filosofía del siglo XVIII debe escribirse largamente, y algún día se escribirá porque merece libro aparte, que puede ser de grande enseñanza y no menor consuelo. La revolución triunfante ha divinizado a sus ídolos y enaltecido a cuantos les prepararon fácil camino; sus nombres, los de Aranda, Floridablanca, Campomanes, Roda, Cabarrús, Quintana (...) viven en la memoria y en lengua de todos; no importa su mérito en absoluto; basta que sirviesen a la revolución, cada cual en su esfera; todo lo demás del siglo XVIII ha quedado en la sombra $(. . .)^{9}$.

A su vez, Ramiro de Maeztu entiende que: «La raíz de la revolución de España, allá en los comienzos del siglo XVIII, ha de buscarse únicamente en nuestra admiración del extranjero. No brotó de nuestro ser, sino de nuestro no ser ${ }^{10}$.

Tampoco supo promover la generación «ilustrada» una cultura independiente de los poderes fácticos; en palabras de Raymond Carr:

La clase «ilustrada» no estuvo a la altura del credo basado en sus supuestos intereses; y es que, en España, la propaganda de las luces no pudo por sí sola

\footnotetext{
7 Enrique Tierno Galván, «Prólogo», en B. Wiese, La cultura de la Ilustración, Madrid, Instituto de Estudios Políticos, 1954, págs. 16 y 17.

8 Américo Castro, Los españoles: cómo llegaron a serlo, Madrid, Taurus, 1965, págs. 138-139.

9 Marcelino Menéndez y Pelayo, Historia de los heterodoxos españoles, Madrid, BAE, 1956, t. II, pág. 667.

10 Ramiro de Maeztu, Defensa de la Hispanidad, Madrid, s.e., 1952, pág. 18.
} 
forjar una burguesía a imagen y semejanza de la francesa, como tampoco pudo la propaganda librecambista, medio siglo más tarde, crear una clase media como la inglesa ${ }^{11}$.

Palacio Atard resume las manifestaciones del Despotismo Ilustrado en cuatro grandes espacios:

En el político-religioso, con un intenso desarrollo del regalismo; en el de la política administrativa, caracterizado por la centralización; en lo económico-social, con amplias y variadas medidas que constituyen un vasto programa de reformas, $\mathrm{y}$, finalmente, en el terreno de la cultura, en el que se procura elevar el nivel cultural y fijar la atención en aspectos científicos hasta entonces no cultivados ${ }^{12}$.

En concreto, lo que los ilustrados como Floridablanca o Campomanes intentaban en España era, en palabras de Elorza:

Una sociedad estamental racionalizada y progresiva. Para conseguir este fin era preciso simplificar y reducir el cúmulo de distinciones y categorías derivadas del pasado histórico y características del Antiguo Régimen. Conservando los principios básicos de estratificación social y las relaciones de producción anteriores, se intentará conseguir la homogeneidad legal, económica y cultural, a fin de que el poder absoluto pueda actuar con plena eficacia; y habida cuenta del desmesurado poder de la Iglesia, tanto en el plano de la conciencia social como en el de la propiedad de la tierra, y su exceso de individuos, con el consiguiente perjuicio para el progreso ideológico y económico, el despotismo ilustrado adoptará una posición secularizada y regalista ${ }^{13}$.

Uno de los rasgos que podría definir casi por sí solo la ideología ilustrada es el afán constante de elevar el nivel de vida de los súbditos, y especialmente de la población rural. Nunca hasta estos momentos se van a plantear en nuestro país de una forma tan decidida ideas como la de «progreso», «bienestar de la colectividad», «riqueza», «lujo» y un largo etcétera, que anuncian la aparición de un sentimiento distinto, de una manera diferente de plantearse la vida y el sentido del hombre.

11 Raymond Carr, España, 1808-1939, Barcelona, Ariel, 1969, pág. 82.

12 Vicente Palacio Atard, «El Despotismo Ilustrado español», en Historia de España, Madrid, 1953, pág. 360.

13 Antonio Elorza, La ideología liberal en la ilustración española, Madrid, Tecnos, 1970, págs. 37 y 38. 
Jovellanos, uno de nuestros ilustrados de más significación, insiste continuamente a través de su larga obra en este sentido nuevo del trabajo en sociedad, así como en el papel del individuo. A modo de ejemplo puede valer esta cita:

El amor a la patria debe ser la primera virtud de todo socio (...) Pero yo no hablo de este amor patrio, que es alguna vez injusto, y por lo común estéril e ineficaz. Hablo sí de aquel noble y generoso sentimiento que estimula al hombre á desear con ardor y a buscar con eficacia el bien y la felicidad de su patria tanto como el de su misma familia; que le obliga a sacrificar no pocas veces su propio interés al interés común; que, uniéndose estrechamente a sus conciudadanos e interesándoles en su suerte, le aflige y le conturba en los males públicos, y le llena de gozo en la común felicidad. Hablo, finalmente, de aquella virtud que en los buenos tiempos produjo a España tantas glorias $(\ldots)^{14}$.

Más adelante explica Jovellanos lo que entiende por felicidad pública:

Cuando digo que la Sociedad debe procurar la felicidad de Asturias, ya se ve que no tomo esta palabra en un sentido moral. Entiendo aquí por felicidad aquel estado de abundancia y comodidades que debe procurar todo buen gobierno á sus individuos. En este sentido la provincia más rica será la más feliz, porque en las riquezas están cifradas todas las ventajas políticas de un estado ${ }^{15}$.

De manera resumida, podríamos decir que las notas fundamentales que caracterizan el ideario de la Ilustración son: razón, naturaleza, libertad y progreso. La razón aparece como un sistema universal y colectivo que alumbra y que da luz a la acción ilustrada. La naturaleza es el receptáculo que todo lo contiene, fuente de vida y de progreso. La libertad y el progreso aparecen dentro de este planteamiento como dos ejes fundamentales de dirección del pensamiento ilustrado. Otras notas del ideario ilustrado a tener en cuenta, y que enlazan perfectamente con las citadas son: paternalismo de gobierno, la filantropía, el amor a la humanidad, el cultivo de las formas peculiares de la sensibilidad, la devoción por la pedagogía y la beneficencia, el desarrollo de las ciencias experimentales y el racionalismo filosófico.

En la actualidad, después de los trabajos de Sarrailh, Maravall, Domínguez Ortiz, Herr, Anes y Elorza, entre otros muchos, sobre el siglo XVIII español, ya no es legítimo señalar a España como la excepción y la nota discordante respecto al movimiento

\footnotetext{
14 Gaspar Melchor Jovellanos, «Discurso dirigido a la Real Sociedad de Amigos del País de Asturias, sobre los medios de promover la felicidad de aquel Principado», en Obras publicadas e inéditas, Madrid, BAE, tomo LV, págs. 438 y ss.

15 Ibidem.
} 
ilustrado europeo de dicho siglo. Las investigaciones realizadas acerca de la labor de las instituciones, el pensamiento y la obra de los ilustrados más insignes y la dinámica de las minorías organizadas, nos permiten subrayar la clarividencia de Sarrailh, uno de los pioneros en el enfoque moderno de la Ilustración española, cuando al referirse a la crítica europea sobre nuestro Dieciocho y la pretendida imposibilidad de equivalencia con otros países de la misma área, dice: «Por eso hemos querido hacer ver que en el siglo XVIII conoció España las mismas aventuras espirituales que las demás naciones europeas, como las había conocido ya en el pasado, como había de conocerlas, una vez más, en época más cercana a la nuestra» ${ }^{16}$.

Por lo que se refiere a la política educativa y a la práctica escolar ilustradas, el mismo autor al que nos referíamos al comienzo de este apartado, Lorenzo Luzuriaga, entiende que sus principales características son las siguientes:

1. ${ }^{a}$ El desarrollo de la educación estatal, de la educación del Estado, con una mayor participación de las autoridades oficiales en la enseñanza.

2. ${ }^{a}$ El comienzo de la educación nacional, de la educación del pueblo por el pueblo o por sus representantes políticos.

3. ${ }^{\mathrm{a}}$ El principio de la educación universal, gratuita y obligatoria en el grado de la escuela primaria, que queda establecida en sus líneas generales.

4. ${ }^{a}$ La iniciación del laicismo en la enseñanza con la sustitución de la enseñanza religiosa por la instrucción moral y cívica.

5. ${ }^{a}$ La organización de la instrucción pública como una unidad orgánica, desde la escuela primaria a la universidad.

6. ${ }^{\mathrm{a}}$ La acentuación del espíritu cosmopolita, universalista que une a los pensadores y educadores de todos los países.

7. ${ }^{\text {a }}$ Sobre todo, la primacía de la razón, la creencia en el poder racional en la vida de los individuos y de los pueblos.

8. ${ }^{a} \mathrm{Al}$ mismo tiempo, el reconocimiento de la naturaleza y de la intuición en la educación ${ }^{17}$.

Si se observan los niveles del sistema educativo español dieciochista y la postura de diversos educadores y responsables políticos, los movimientos educativos citados no se dan de forma homogénea ni todos por igual en la realidad educativa española y bastantes de ellos sólo se desarrollarán en los siglos siguientes. Así, por ejemplo, la educación estatal tal como la concibe Luzuriaga se puso en marcha en buena parte y se advierte una mayor participación del Estado en la

16 Jean Sarrailh, La España ilustrada de la segunda mitad del siglo XVIII, Madrid, F.C.E., 1974, pág. 11.

17 Lorenzo Luzuriaga, op. cit., págs. 152 y ss. 
enseñanza, aunque las instituciones eclesiásticas seguirán teniendo bastante poder en todos los niveles educativos. Pero, la educación nacional entendida como la educación del pueblo por el pueblo, o la aplicación de los principios de universalidad, gratuidad y obligatoria de la enseñanza primaria, tardaría aún bastante para ser aplicados en la práctica, especialmente dadas las condiciones económicas e ideológicas de la época.

No fue fácil iniciar la aplicación del laicismo en al enseñanza, aunque Cabarrús, por ejemplo, lo defiende en su Carta II, al igual que defiende la educación estatal y la educación nacional, pero hay que recordar que estaba considerado como un radical afrancesado. Tampoco durante el siglo XVIII se consigue plantear la instrucción pública como una unidad orgánica y, de hecho, habrá que esperar al siglo XIX para que se empiece a avanzar en este ámbito. Las otras tres características, espíritu cosmopolita, primacía de la razón, y reconocimiento de la naturaleza y la intuición en la educación, sí que fueron siempre principios defendidos por la minoría ilustrada.

Podemos decir, como resumen, que las tendencias expuestas por Luzuriaga son de carácter general para el movimiento ilustrado, pero no se dieron todas al mismo tiempo ni se consiguió avanzar en cada una con la misma celeridad. Especialmente en Francia, con el movimiento surgido en torno a la Enciclopedia y la Revolución francesa, sí que se dieron algunas de esas características con mayor prontitud. La tendencia estatista en la educación se desarrolla antes en Alemania, donde también se aplica primero la obligatoriedad escolar y la secularización de la educación, haciéndola independiente de la Iglesia. La educación pública estatal comienza en Francia con la expulsión de los jesuitas en 1762 y con los estudios favorables de La Chalotais, Turgot, Montesquieu, Diderot y Rousseau; la educación nacional llegaría de la mano de Talleyrand, Mirabeau, Codorcet y Lakanal, entre otros, todos ellos conocidos por los ilustrados españoles. No obstante, también en Francia tendrían que esperar al siglo XIX para ver muchas de las ideas proyectadas hechas realidad.

En el conjunto del país se detecta una enorme separación entre las minorías ilustradas y el pueblo español, entre los dirigentes y los gobernados, entre la masa y la minoría que dijera Jean Sarrailh en su conocida obra La España ilustrada de la segunda mitad del siglo XVIII ${ }^{18}$; se intentó cambiar ese estado de cosas y entre 1760 y 1788, aproximadamente, se avanzó bastante en cuestiones de crecimiento económico y reformas industriales como en un claro proceso de ilustración del pueblo español y liberalización política, pero la década final del

18 Jean SArrailh, La España ilustrada de la segunda mitad del siglo XVIII, op. cit., «La masa y la minoría», págs. 17 y ss. 
siglo se cerró con un fracaso porque los reformistas no estuvieron en condiciones de alterar las bases sociales y económicas de la sociedad estamental y los privilegios tradicionales ${ }^{19}$.

No se consiguió en buena medida lo que Fernando Álvarez-Uría afirma que los ilustrados españoles se plantearon:

En primer lugar, la extirpación de los malos hábitos, la persecución de la superstición y la ignorancia, y la abolición de viejos prejuicios enquistados como la peste en las costumbres del pueblo, exclusión, en fin, de los viejos errores heredados del pasado y que han hecho del vulgo un pueblo rudo e inculto. A esa operación de higiene y policía sigue otra de jardinería de masas, es decir, una política de reterritorialización y control que pretende concurrir a la vez a la quietud del Reino y al aumento de la felicidad pública. Depurada y distribuida la población, regulado su funcionamiento expedito, asegurado el trabajo de cada uno en beneficio de la riqueza material y moral de toda la colmena, se producirá, como por decurso natural, el incremento de la fortuna y con ello, el triunfo de una nueva era. Las Luces brillarán al fin rutilantes en el nuevo panorama social ${ }^{20}$.

Pero, ¿cuál era la realidad de la enseñanza primaria española en el siglo XVIII? La población española, teniendo en cuenta los censos de Aranda, Floridablanca y Godoy, así como el Catastro del marqués de la Ensenada de 1749, pasó de 9,3 millones de personas hasta 11,5 millones en 1797, con una densidad media situada entre los 21 y 23 habitantes por kilómetro cuadrado en 1787 , aunque ofreciendo fuertes contrastes regionales. Con una esperanza de vida al nacer de 27 años. La tasa bruta de natalidad sería del 42 por 1000 y la tasa de mortalidad del 38 por 1000, siendo la tasa de crecimiento del 0,4 por 100 .

La población en posible edad escolar de la época, según las diversas estadísticas conocidas, era la siguiente:

$\begin{array}{ccc}\text { Censo de Aranda }(1768-69) & \text { Varones } & \text { Mujeres } \\ \text { Hasta siete años } & 842.383 & 823.616 \\ \text { De } 7 \text { a l6años } & 829.238 & 782.984\end{array}$

Censo de Floridablanca (1787)

$\begin{array}{lll}\text { Hasta siete años } & 957.048 & 915.464 \\ \text { De } 7 \text { a } 16 \text { años } & 928.263 & 878.470\end{array}$

19 Fernando Álvarez-Uría, «La Ilustración y su sombra. Dominación cultural y pedagogía social en la España del Siglo de las Luces», en Revista de Educación, Madrid, núm. extraordinario de 1988, págs. 345 y ss.

20 Ibidem. 
Según el censo de Floridablanca, sabemos que entre niños y niñas comprendidos entre uno y siete años de edad había 1.872.512 personas, y también que el número solamente de varones entre uno y dieciséis años de edad venía a ser de 1.885.311 personas. Resulta sorprendente que, según el Censo de Godoy, hecho diez años más tarde, el número de escuelas en el país fuera de 8.704 y el de maestros, de 8.962, a pesar de los aumentos de población del período.

Algunos datos del censo de Godoy:

$\begin{array}{lrrc} & \text { Niños } & \text { Niñas } & \text { Total } \\ \text { Número de escuelas } & 8.704 & 2.303 & 11.007 \\ \text { Número de maestros } & 8.962 & 2.575 & 11.537 \\ \text { Número de alumnos } & 304.613 & 88.513 & 393.126\end{array}$

Los 393.126 alumnos suponen una tasa de escolarización del 23,3 por 100 para la población de 6 a 13 años, si bien estudiaba el 36,4 por 100 de los niños frente al 10,39 por 100 de las niñas. En cualquier caso, se observa el avance de la escolarización y alfabetización en términos absolutos en la segunda mitad del siglo XVIII y un mayor interés por las cuestiones relacionadas con el aprendizaje y uso de la lectura y escritura, así como un incremento de la demanda y oferta de los instrumentos básicos para su aprendizaje ${ }^{21}$.

Hasta aquí el panorama de la Ilustración española y de la educación y la pedagogía del momento, como contexto en el que surgirán los diferentes tipos de maestros propios de la situación. Durante buena parte del siglo el magisterio popular estuvo formado por maestros tradicionales, dependientes de la concepción gremial imperante, y progresivamente por los maestros escolapios. Habrá que esperar al último tercio del siglo XVIII para ver aparecer con fuerza al maestro moderno propio de la Ilustración, que pretendía erigirse en el maestro por excelencia, el que correspondía a la ideología ilustrada, superando al maestro tradicional y también al religioso.

\section{El maestro tradicional}

El maestro tradicional es el correspondiente al Antiguo Régimen, cuando aún no habían entrado en consideración de una manera determinante los planteamientos ilustrados para la formación de los maestros. Era un maestro sin

\footnotetext{
21 Vid. Antonio VIÑAO, «Alfabetización e Ilustración. Difusión y usos de la cultura escrita», en Revista de Educación, Madrid, núm. extraordinario, 1988, págs. 289 y ss.
} 
formación específica ligado a la Hermandad de San Casiano, es decir, al gremio correspondiente a la enseñanza, que como es bien sabido, se estableció hacia 1642 cuando los maestros de «escribir y contar» de la Villa y Corte de Madrid decidieron crear «una Congregación o Cofradía para su mutuo auxilio y de sus viudas y huérfanos, bajo la advocación de San Casiano». A través de esta organización los maestros empezaron a reivindicar la posibilidad de intervenir en todo lo referente a su oficio ${ }^{22}$.

¿Qué condiciones se exigían para ser maestro? Las condiciones para acceder a un puesto docente eran las de ser hijodalgo, cristiano viejo, no tener mezcla de sangre de moro, turco o judío, disfrutar de buenas costumbres y no haber sido penitenciado por el Santo Oficio ni ser converso reciente ${ }^{23}$. En 1705 se incluye la limpieza de linaje, no haber ejercido oficios mecánicos y no haber sufrido pena de infamia. En la Real Provisión de Carlos III del año 1771 se manda que para ser admitido a maestro de primeras letras los candidatos deberán cumplir estas condiciones: «presentarán o harán información de tres testigos, con citación del Síndico Personero ante la Justicia del lugar de su domicilio, de su vida, costumbres y limpieza de sangre; a cuya continuación informará la Justicia sobre la certeza de estas cualidades».

En la Real Provisión del 20 de diciembre de 1743 se clasifica a los maestros en tres grupos con distintos exámenes para los que fueran a ejercer en Madrid, en poblaciones grandes, $o$ en aldeas y villas ${ }^{24}$. El primer examen, que se pedía para los futuros maestros de Madrid, se debía realizar según la Real Provisión de 1719 y en él se exigía:

-En lectura, el conocimiento de la letra romanilla, de molde y de coro o bula, el de letra manuscrita antigua y el deletreo de las cartillas.

-En escritura se debía conocer y dibujar las letras, bastarda, grifa, romanilla, redonda y libros de coro; en ortografía, lo más necesario.

-En aritmética, las cuatro reglas fundamentales en enteros y quebrados, extracción de raíces cuadradas y cúbicas, las reglas de tres, falsa posición y aligación de mezclas.

22 Véase el libro de Clotilde GuTiÉRrez, Enseñanza de primeras letras y latinidad en Cantabria (17001860), Santander, Universidad de Cantabria, 2001, págs. 52 y ss. Más datos en Francisco Aguilar Piñal, «La enseñanza primaria en Sevilla durante el siglo XvIII», en Boletín de la Real Academia de Buenas Letras de Sevilla, 1973, págs. 40 y ss.

23 Para hacer el seguimiento de las normas elaboradas para regular el magisterio en este período es recomendable acudir directamente a las fuentes: Novísima recopilación, Libro 8, título 1, diversas leyes; también a través del libro de Lorenzo Luzuriaga, Documentos para la historia escolar de España, Madrid, Junta para Ampliación de Estudios e Investigaciones Científicas, Centro de Estudios Históricos, 1916.

24 El segundo examen consistía en valorar los conocimientos que los aspirantes tuvieran de «lectura, escritura, ortografía, elementos de aritmética y arte de gobernar a los niños». El tercer examen comprendía las mismas materias que el anterior, pero con menor extensión. Lorenzo LuZuRIaga, Documentos para la historia escolar de España, op. cit., y Novísima Recopilación, op. cit., libro 8. 
—En Doctrina Cristiana, el contenido del catecismo de Ripalda, especialmente los misterios.

En un primer momento, los examinadores eran nombrados por el corregidor de Madrid, a propuesta de la Hermandad de San Casiano. Tal facultad se trasladó al Consejo aunque seguían siendo propuestos por la Hermandad. En realidad, buena parte del examen de maestro se centraba en la escritura, mientras que la parte dedicada a ortografía y a aritmética era breve.

El maestro español tradicional del Antiguo Régimen sólo realizaba el aprendizaje gremial previo a su colocación y no recibía una formación teórica y sistemática de su profesión ${ }^{25}$. Se trataba de una formación práctica de acuerdo con las reglas más clásicas entonces en el aprendizaje de oficios. El futuro maestro urbano, de las ciudades y pueblos destacados, estaba en contacto con la realidad escolar desde pequeño, desde que entraba en la misma escuela. Terminados sus estudios en ella, si mostraba adelantamientos adecuados para aquel tipo de enseñanza, continuaba en la misma clase o entraba de ayudante con otro maestro. En la práctica, muchos maestros no salieron de la escuela desde que entraron en ella, con unos seis años, hasta que sustituyeron a su titular por fallecimiento o bien el gremio les admitió como titulares en otra plaza.

Estos maestros urbanos estaban controlados por su propio gremio o por las autoridades locales y siempre inspeccionado por los representantes de la Iglesia, sabían leer, escribir, algo de aritmética y la Doctrina Cristiana siguiendo el catecismo de Astete. Eran ante todo calígrafos, pendolistas, que estaban en condiciones de repetir muy bien textos escritos, pero no se podía estar seguro de cuáles eran sus conocimientos gramaticales ni si sabían utilizar adecuadamente las reglas ortográficas.

Como su sueldo era escaso, tenían que recurrir a otros empleos para poder vivir con cierta dignidad. Si bien no todas las ocupaciones que podían desempeñar estaban relacionadas con la docencia, a excepción de la de impartir clases particulares de segunda enseñanza. Sí tenían el derecho a desempeñar ciertas actividades como las de pendolistas y revisores de letras, que mencionan las Ordenanzas de 1695 y 1705 y las Provisiones de 1743 y 1797, y también las de escritores de privilegios y lectores de letra antigua a que alude el Reglamento de $1797^{26}$.

25 Julio Ruiz Berrio, «La educación del pueblo español en el proyecto de los Ilustrados», en Revista de Educación, Madrid, núm. extraordinario de 1988, págs. 163 y ss. ; véase también del mismo autor: «La crisis del profesor español en la Ilustración», en Educación e Ilustración. Dos siglos de Reformas en la Enseñanza, Madrid, MEC, 1988. Además de los trabajos citados, ambas publicaciones, aparecidas dentro de la conmemoración del segundo centenario del fallecimiento de Carlos III, contienen interesantes estudios en torno a la centuria ilustrada en el ámbito educativo.

26 Lorenzo LuZuriaga, op. cit., págs. XXXVII y ss. 
Estos maestros que habían conseguido su puesto después de superar un examen y que podían desempeñar algunas otras actividades, tenían una posición social y económica humilde pero, a pesar del tópico al uso, no se puede decir que pasaran hambre. Los maestros que se llevaban la peor parte eran los maestros rurales que recibían a veces su sueldo de por sí escaso con retraso de meses o años. Salían adelante gracias a su dedicación a otros oficios, como sacristán, secretario del Ayuntamiento o tabernero. La lucha constante de estos maestros será conseguir que fuera el Estado y no los ayuntamientos los que se encargaran de pagar sus sueldos, pero, como es sabido, esta aspiración tardaría aún bastante tiempo en alcanzarse.

La situación de las pocas maestras existentes en el Antiguo Régimen era aún más precaria ${ }^{27}$. En general, ni siquiera sabían leer y escribir, ya que no habían ido a la escuela de pequeñas, y se solían saber de memoria el catecismo religioso y enseñaban a las niñas las principales oraciones de la religión católica y las costumbres piadosas y en muchas ocasiones a coser y a bordar. El sueldo que percibían, cuando lo recibían, era aún menor que en el caso de los maestros y sin embargo, se esperaba de ella que fueran modelos de mujeres cristianas, buenas amas de casa y esposas, como manera de dar ejemplo a sus alumnas.

\section{El maestro ilustrado}

Aunque se conocen proyectos reformadores desde comienzos del siglo ilustrado, es con Carlos III cuando se observa la aplicación de una política escolar renovadora, cuando se pone en marcha la reforma de los estudios, según se decía entonces. Convencidos del poder transformador de la educación, los ilustrados españoles se plantean extender los conocimientos elementales a todos los súbditos, y para ello entiende que primero es preciso modernizar la enseñanza elemental, dotándola de un método, libros de textos didácticos y profesores preparados. Pero, como veremos a continuación, tales objetivos sólo se consiguen parcialmente.

Los tres criterios de la reforma que se pretendía llevar a cabo eran: uniformidad de la enseñanza, modernización de los métodos pedagógicos y secularización

27 A este respecto resulta esclarecedor el libro de Sonsoles SAN Román, Las primeras maestras. Los orígenes del proceso de feminización docente en España, Barcelona, Ariel, 1998. Se recomienda, especialmente, la lectura de la primera parte, «La educación de la mujer en el proyecto de los ilustrados: fundamentos teóricos», pág. 19 y ss., y de la segunda, «La maestra analfabeta en los albores de la educación de la mujer en España», págs. 47 y ss. 
progresiva de los estudios ${ }^{28}$. Se puede observar la importancia de cada uno de los criterios para, de una parte, modernizar la educación, especialmente dándole uniformidad e introduciendo nuevos métodos pedagógicos, y de manera complementaria, avanzar en la secularización de la vida y la escuela españolas, monopolizadas por la Iglesia católica. Pero, como veremos, aún durante bastante tiempo la teoría iría por una parte y la realidad educativa por otra. En cualquier caso, con el reinado de Carlos III se ponen las bases a la modernización educativa de España, siguiendo las políticas educativas que ya se empezaban a aplicar en otros lugares de Europa.

A veces no se recuerda suficientemente la importancia que pudo tener en nuestros ilustrados la lectura de El verdadero método de estudiar para ser útil a la República y a la Iglesia, de Luis A. Verney. Es una crítica a la enseñanza en las escuelas de Portugal y un planteamiento de la reforma necesaria para superar métodos anticuados de la escolástica y el bajo nivel académico, que se traduce al castellano en 1760 y que, por analogía con la situación educativa española, influyó bastante en la polémica entre tradición y modernidad y en la búsqueda de una alternativa educativa ilustrada ${ }^{29}$.

La obra de Verney, junto a muchas otras publicaciones de novatores y la importante producción feijoniana, coinciden todas en la crítica a los métodos y a las enseñanzas tradicionales y, exponiéndose a los riesgos de ser enjuiciados por la Inquisición y ganarse la enemiga de las órdenes religiosas predominantes, se alinean con las tendencias filosóficas y científicas modernas, casi siempre de origen inglés y francés, aún sin abdicar de su formación y principios cristianos. Todos ellos insisten en las palabras esenciales de progreso, desarrollo o fomento nacional, razón, modernidad, pragmatismo y experimentación y están preparando el camino para las generaciones posteriores de ilustrados que tendrían en ellos su referencia principal y punto de partida.

En otro orden de cosas, a la Hermandad de San Casiano como representación institucional gremial, propia del Antiguo Régimen, le sustituyen el Colegio Académico y la Academia de Primeras Letras en un intento de modernizar la formación del profesorado dentro del proyecto ilustrado. Ya en 1774, desde la propia Hermandad, se propuso su transformación en Colegio Académico al Consejo de Castilla. Se consiguió finalmente en 1780, al aprobarse los estatutos

28 Francisco Aguilar Piñal, Introducción al método de estudios de Trigueros, Barcelona, Departamento de Educación Comparada e Historia de la Educación, Universidad de Barcelona, 1984, pág. 3.

29 El libro consta de dieciséis cartas distribuidas en cuatro tomos en las que Verney se muestra crítico con la tradición y apoya, tanto en métodos como en contenidos, las nuevas corrientes intelectuales y científicas europeas que entiende deben aplicarse en Portugal. Más datos en nuestros libros: Olegario NEgrín, Veinticinco ensayos de historia de la educación española moderna y contemporánea, Madrid, UNED, 2005, y Olegario NEgrín, Historia de la educación española, Madrid, UNED, 2006. 
del «Colegio Académico de Profesores Maestros del Noble Arte de las Primeras Letras de esta Corte $»^{30}$. Así comienza de una manera intencional y sistemática la preparación teórica de los maestros, a través de una reunión o clase en la que se explicaban las lecciones semanales. Los alumnos eran los 24 leccionistas de la Corte y los profesores eran los maestros colegiados. Las materias tratadas en los ejercicios eran gramática, aritmética y lectura.

Se puede decir que este Colegio era un avance respecto a la Hermandad de San Casiano, puesto que la enseñanza recibida por los futuros maestros no era la propia del gremio, aprender al cabo de los años junto a otros maestros, sino que ahora, además de los años de pasantes, se mostraba la preocupación por dar las bases teóricas de la profesión, en sus materias más significativas, y sobre todo se planteaban criterios y principios ilustrados dirigidos a fomentar en los niños el trabajo y la producción, para tratar de desterrar el ocio y la mendicidad y lograr así un mayor adelantamiento en la industria nacional y la felicidad pública.

Para conseguir sus objetivos, el Colegio Académico dispuso que, a partir del curso escolar 1783- 84, en las tardes de los jueves se cerraran las escuelas con el fin de que todos los enseñantes participaran, durante el invierno de dos a cinco de la tarde y en verano de cuatro a siete, en dichos ejercicios académicos que consistían en:

Tratar de la gramática española, de los escritos y carácter de letra que se han usado y usan en el Reino, de la aritmética universal, de la comprobaci6n y cotejo de manuscritos, y de todo lo demás que parezca útil para la perfecta educación pública... Cada Académico profesor tendrá a su cargo, en calidad de catedrático, un ejercicio por su antigüedad y turno, y como sustentantes, asistirán a él, uno de los 24 leccionistas, por el mismo orden y turno; sin que por ello dejen de concurrir a los ejercicio todos los demás Académicos y Discípulos, reservando, por ahora, el Colegio acordar todo lo demás que en lo sucesivo considere oportuno, para el mayor adelantamiento y perfeccionamiento en los ejercicios, presentándose ante el Consejo para su aprobación, pues sin ello no puede ponerse en ejecución ${ }^{31}$.

Aunque, al parecer, la experiencia ilustrada tuvo escaso éxito en la práctica $^{32}$, la idea del Colegio Académico era que tales reuniones tuviesen una fun-

\footnotetext{
$30 \quad$ La decisión en tal sentido fue tomada por Real Cédula de 22 de diciembre de 1780.

31 Estatuto del Colegio Académico de Nobles Artes de primeras letras, aprobado por el Supremo Consejo de Castilla en 22 de diciembre de 1780, Madrid, Isidoro Fernández Pacheco, Impresor y Librero, 1781, pág. XLIX.

32 Carta firmada por un pasante de maestro en El Correo de Madrid el 31 de julio de 1790. Afirma en ella que su realidad era inexistente, que sus libros de actas estaban vacíos y que los asuntos que se trataban no eran precisamente académicos, pues él llevaba ya cuatro años asistiendo y no había aprendido nada de utilidad.
} 
ción pedagógica de carácter práctico, basada en la comunicación de experiencias entre los maestros veteranos y los maestros en formación.

El programa para la enseñanza primaria defendido por los ilustrados y que se impartía en la España de la época se centraba en la enseñanza de las siguientes materias: Lectura, Escritura, Cálculo y Doctrina Cristiana. Ya en 1771 se podía leer en una orden oficial: «Que en las escuelas se enseñe, además del pequeño y fundamental catecismo que señale el Ordinario de la diócesis, por el compendio histórico de la Religión de Pintón, el Catecismo histórico de Fleury, y algún compendio de la historia de la nación ${ }^{33}$.

La forma más común para el aprendizaje de la lectura en la España de la época era la que se realizaba en voz alta; así lo pone de manifiesto José Anduaga, cuando indica que:

Los niños apenas entran en la escuela ocupan su asiento, y allí están, casi las tres horas, deletreando ó leyendo en voz alta, confundiéndose entre sí; y causando un murmullo que puede llamarse gritería, incómoda al Maestro é insufrible a los vecinos. Después que los niños han gastado de este modo el tiempo de su lección, pasan a darla, ó, por mejor decir; á repetirla delante del Maestro ${ }^{34}$.

En el mes de junio de 1788 se creó la llamada «Escuela de la Real Comitiva», bajo la protección de la Corona. Se destinaba a los hijos de los criados y menestrales que acompañaban al Rey en sus visitas por los Reales Sitios. De esta enseñanza se encargaba a Juan Rubio, cuyo método debería seguirse en la citada escuela. Así empezó la difusión de un movimiento cuyos orígenes se remontaban a 1780, cuando un diplomático de carrera, José Julián Anduaga y Garimberti, se planteó renovar el tipo de enseñanza al uso, y pudo hacerlo merced a la autorización del conde de Floridablanca en las escuelas de los Reales Sitios de San Ildefonso y Valsaín ${ }^{35}$.

Lo primero que decidió fue encontrar un método nuevo para la enseñanza de la escritura y pensó en la racionalización de tal enseñanza, elaborando una serie de reglas que permitieran al aprendiz encontrar sentido y fuera la base para todo tipo de letras. Anduaga estimaba que quien supiera por principios las verdaderas proporciones de todas las letras, minúsculas y mayúsculas, sabría el verdadero arte de escribir. Surge así la polémica entre Anduaga, creador del método de San Ildefonso, y el calígrafo Torio de la Riva, acerca de si se debía enseñar a escribir

\footnotetext{
33 Real Provisión de Carlos III, dada el 11 de julio de 1771.

34 José Anduaga, Arte de escribir por reglas y sin muestras, Madrid, 1795, pág. 67.

35 Más datos en Julio Ruız, «La educación del pueblo español en el proyecto de los ilustrados», art. cit., pág. 182.
} 
mediante reglas y sin muestras o bien con reglas y con muestras, que atrajo la atención de las autoridades y de los maestros, que comprendieron la importancia de la aplicación de la nueva metodología ${ }^{36}$.

El proceso reformador llegó a su máximo desarrollo en 1791 con dos creaciones destacadas $^{37}$. Una, la de las ocho Escuelas Reales, una en cada uno de los ocho cuarteles en que se estructuraba Madrid. Se trataba de escuelas con carácter gratuito, que recibían a los alumnos pobres que enviaran las Diputaciones de Caridad y que se caracterizaban por seguir el método de San Ildefonso. A su vez, también se convertían en centros-modelo para las demás escuelas del reino. De su supervisión se encargó a Juan Rubio, como visitador. La otra fundación importante fue la de la Real Academia de Primera Educación, convertida en un organismo nacional dirigido por Anduaga y con la misión de renovar toda la enseñanza de primeras letras en España, proporcionando un método a las escuelas y prestando una formación profesional a los maestros. Aunque nació con la pretensión de suprimir el Colegio Académico se cerró en 1800 al fusionarse con él.

La importancia del movimiento de San Ildefonso, a pesar de su corta existencia, está en su explícita preocupación por lograr una enseñanza de calidad y no sólo una ampliación cuantitativa del número de alumnos, profesores y escuelas. Las polémicas sobre los métodos para la enseñanza de la lectura y escritura no eran, por otra parte, una cuestión meramente pedagógica. En torno a la enseñanza de la escritura se alineaban dos bandos, los palomaristas, calígrafos, y los anduaguistas, maestros. Para el portavoz de los primeros, Torio de la Riva, la caligrafía era toda una disciplina y un arte del dibujo, del trazo y de la belleza, se aprendía mediante la imitación y la copia. Su obra fue escrita en respuesta a la de Anduaga que rechazaba la imitación o copia de muestras, prescribiendo unas reglas y un método, en su opinión, más fácil y sencillo que permitía ciertas diferencias individuales en el tipo de letra, según el gusto, pulso y genio de cada uno, y una escritura más simplificada.

Pero ¿̨cuál fue el alcance de estos debates? Al parecer no pasó de ser una experiencia aislada, lo que puede explicar el testimonio del obispo entonces de Osma, Antonio Tavira, que afirma en una carta al rey de 1797:

Las escuelas de primeras letras, por lo común, están muy decaídas, ya excepción de alguna provincia del reino en donde hay algún esmero en esta parte, en todas las demás se mira este punto con indolencia. Los niños salen de ellas, después de

\footnotetext{
36 Ibidem.

37 Ibidem, págs. 183 y ss.
} 
no pocos años, leyendo mal y escribiendo peor; y sin otros conocimientos, porque los maestros carecen de ellos, y cuando más, han aprendido materialmente lo que dice un breve y descarnado catecismo por la rutina de decirlo y cantarlo en ciertos días. y aquí termina la educación que se puede decir nacional, porque la(que)se continúa después en los estudios públicos es para una porción de individuos muy pequeña, si se compara con la de los que no los siguen $^{38}$.

También en la prensa del siglo XVIII se encuentran muchos documentos que aluden a la escasa formación de los maestros; entre ellos destaca la «Carta del Maestro Cascaciruelas» de 1789, destinada a los aprendices de maestros:

Muy Señores míos, pero de poco dinero: Me parece que les veo a todos Vms. tan parecidos a mí cuando estaba de candidato a maestro como Vms. al presente... porque les miro lleno de compasión, con síntomas nada equívocos del hambre más peliaguda, sin oficio ni beneficio, azotados de la necesidad y cargados de la ineptitud para obtener empleo alguno que sea de algún honor o requiera alguna habilidad de entendimiento o de manos... Les miro, digo, casados la mayor parte por fuerza, que a no ser esto, el fusil hubiera acogido a más de cuatro que la palmeta... les doy estos avisos y consejos nacidos de mi mucha experiencia, con el fin de que puedan ser tan maestros como yo, el día de mañana, sin matarse a estudiar ni a cavilar en nada de aquello que dicen algunos que consiste el verdadero Magisterio de primeras Letras... Pero sobre todo, Caballeros, el valer y respetar es todo el caldo gordo de esta facultad. Hombre a quien no tiemblen desde una legua los muchachos, y con sólo presentarse en la escuela o en cualquier casa, no infunda miedo su prospecto, digo yo que no vale tres caracoles... Pero, sobre todo, vamos claros, nada es más del caso para el gobierno nuestro, como la suma diligencia en cobrar nuestro trabajo, porque en la era presente no hay trampas menos perseguidas y más autorizadas que las que se contraen con el maestro... Si existen tasas para comprar cosas de escuela... componer una ayuda de costa. En fin, al que sea ingenioso no le faltarán medios de buscar qué comer... Pues con estos consejos se verán ustedes el día de mañana, Maestros por esas Villas y Lugares, con tantas o más ínfulas que yo, sin haber aprendido más que un tal cual leer, escribir y contar para el gobierno del aguador y lavandera, cuando la haya. Y echad un ojo por tantos Discípulos como repartidos tengo por ese mundo, casados unos, Frailes otros, Soldados los más, que no cesan de dar gracias por haberles sacado hombres, los azotes de mi escuela. Y dando gracias a Dios por haber logrado un tal padre y aconsejador, observad, Caballeros míos, mis máximas, mientras que yo, gozoso de dejar tantos semejantes

38 Citado por Julio Ruz, «La crisis del profesor español de la Ilustración», art. cit., pág. 230. 
míos, muero con tranquilidad y en la esperanza que me recomendarán a Dios, quien guarde a Vms. tantos años como desea su verdadero y afectísimo servidor. El Maestro Cascaciruelas ${ }^{39}$.

Dos ejemplos de maestro ilustrado en la literatura pedagógica de la época

La realidad escolar de finales del siglo XVIII era bastante criticada, ello no era obstáculo para que los ilustrados siguieran teorizando sobre cuál era el mejor sistema de enseñanza o cuáles deberían ser las funciones de un maestro moderno. Veamos a este respecto dos ejemplos concretos de la literatura de la época. La primera propuesta de maestro ilustrado es la que hace Viera y Clavijo ${ }^{40}$, un clérigo canario del siglo XVIII, que fue preceptor en Madrid del hijo del marqués de Santa Cruz. Pero, quizás, el ejemplo más claro del prototipo de maestro ilustrado laico es el que presenta Francisco Cabarrús ${ }^{41}$ en la Carta II de las que dirige a Godoy con el expresivo subtítulo «Cartas sobre los obstáculos que la naturaleza, la opinión y las leyes oponen a la felicidad pública» ${ }^{42}$.

Viera y Clavijo, al comienzo de uno de los memoriales o capítulos en los que subdivide su escrito, en línea con el pensamiento ilustrado de reforma de la enseñanza, afirma:

El que conoce la gran necesidad que tenemos de maestros hábiles, capaces de enseñar a leer y escribir bien e imagina que ésta se podría remediar introduciendo en el País una nueva orden religiosa, es fértil en recursos; pero quizás no es muy político, ni entiende los verdaderos intereses de la Patria. Tenerife no se halla ciertamente en estado de hacer unos esfuerzos tan gravosos, que acaso harían saltar en pedazos el resorte tan sobrenatural que sostiene el demasiado peso que la oprime. Así, dejándonos de ideas, verdaderamente magníficas, pero buenas para otros siglos, tengamos la prudencia de pensar en el asunto con más economía y menos entusiasmo ${ }^{43}$.

39 Véase Carmen Labrador, Juan Carlos de Pablos, La educación en los Papeles Periódicos de la Ilustración española, Madrid, Ministerio de Educación y Ciencia, 1989, págs. 156-160.

40 La perspectiva educativa de Viera puede consultarse en: Olegario NEGRín, «José de Viera y Clavijo», en Olegario Negrín (dir.), Historia de la educación en España, op. cit., págs. 161-168.

${ }_{41}$ Vid. Olegario Negrín, «Francisco Cabarrús», en Olegario NEGrín (dir.), op. cit., págs. 193 y ss., y «La Carta II de Francisco Cabarrús, una alternativa pedagógica al sistema educativo español de finales del siglo XVIII», art. cit., págs. 47-69.

42 Francisco Cabarrús, Cartas sobre los obstáculos que la naturaleza, la opinión y las leyes oponen a la felicidad pública. Estudio preliminar de J.A. Maravall, Madrid, Castellote, 1973.

43 José Viera y Clavijo, El Síndico Personero General. Obra patriótica escrita periódicamente en la ciudad de La Laguna. Edición, estudio introductorio y notas de Olegario Negrín Fajardo, Las Palmas, Ediciones del Cabildo Insular de Gran Canaria, 1994, Memorial segundo, págs. 83-84. 
¿Qué maestro está buscando y propone en sus memoriales el clérigo ilustrado canario? En sus palabras:

Un hombre que sepa leer con sentido, que enseñe la doctrina cristiana, especialmente por el catecismo de Fleury, que imponga a los niños en todo género de buenos modales y de decoro; que tenga algunas muestras de letra limpia, y que al tiempo que instruye a los demás se instruya a sí mismo en el librito de la ortografía de la lengua castellana, no es un hombre muy extraordinario, y si se saben buscar se hallarán muchos ${ }^{44}$.

Uno de los tantos elementos singulares de El Personero es su concepción del placer unido al juego, seguramente en aplicación de las entonces conocidas tesis modernas de Rousseau:

¿Qué placer para un buen padre, un buen ciudadano o un buen regidor sería observar a los niños de tres o cuatro años, empezando a conocer las letras, a juntarlas, y a hacer de ellas un inocente juego! Llámolo juego porque dos cosas debe encargar V.S. al maestro con mucho cuidado. La una, que no presente desde luego la lectura a los niños, como un trabajo serio, pues ciertamente su edad no sufre estas formalidades; y la otra, que no se enfade con ellos ni los castigue, aunque vea que no hacen unos progresos rápidos ${ }^{45}$.

Viera es muy optimista cuando se imagina que los maestros dedicarán su tiempo libre a estudiar los manuales más recomendables para la educación de las nuevas generaciones isleñas. Esto es lo que afirma:

Un preceptor aprovechará los instantes de ociosidad en la lectura de buenos libros. Él pasará las noches sobre el Catecismo Histórico de Fleury, sobre El Espectáculo de la Naturaleza y sobre el Teatro Crítico Universal. Él formará el juicio de sus pequeños discípulos y estará en centinela contra los errores comunes, que en la niñez ganan en nosotros un terreno importante que conservan toda la vida ${ }^{46}$.

Parece que Viera prefiere también en el momento del aprendizaje de la escritura los métodos ilustrados más eficaces, aunque a lo mejor no sean los que persiguen la mejor estética:

$44 \quad$ Ibidem, pág. 85.

45 Ibidem, pág. 86.

46 Ibidem, págs. 87-88. 
Cuando los niños empiezan a escribir haga V.S. que sus maestros les presenten modelos de una letra limpia, clara, sin rasgos ni perfiles y en donde reine la buena ortografía y las máximas agradables... Que no se mate mucho por la hermosura de los caracteres: que no malogre en esto un tiempo precioso, digno de aprovecharse en cosas más útiles. Que se contente con que el discípulo tenga una mano ligera y que sean inteligibles sus planas; pues más hará un muchacho después, cuando tuviese formado el gusto en cuatro meses, que antes ni en cuatro ni en cinco años ${ }^{47}$.

Muestra también nuestro autor mucha preocupación por el uso de la correcta ortografía:

Si los que leen un libro moderno observasen las letras con que están escritas sus dicciones; si se aplicasen a lo menos un mes a no escribir sino con toda la reflexión posible; y si se procurase leer el librito de la ortografía castellana, que la Academia de la Lengua dio a luz en Madrid y en cuyo trabajo tuvo mucha parte un ilustre hijo de Tenerife, todos escribiríamos correctamente y no nos desautorizaríamos a nosotros mismos y a nuestras producciones ${ }^{48}$.

Finalmente, se inclina por la inspección de las escuelas por las autoridades a las que sugiere motivar y animar a los niños para que les sea provechosa la instrucción:

Dije que V.S. pudiera visitar las escuelas públicas donde aprenden los niños, y no espero que se desprecie el pensamiento. Amable juventud, cuando el llustre Ayuntamiento de Tenerife se declare abiertamente por tu protector y tu padre, cuando te enviare cada dos meses una diputación respetable, con designio de saber el estado de tus progresos; y a informarse de los niños que más se distinguen en leer, escribir y penetrar los misterios de la religión y de la urbanidad, entonces tú serás feliz. Entonces tú recibirás de tu Cabildo, por el órgano de sus diputados, aquellos elogios que encienden la tierna emulación y aquellas reprensiones suaves que la estimulan. Sí, Señor, una visita, un elogio, una estampa, un libro de oro falso o una bagatela brillante es capaz de desenvolver, en un muchacho, toda la habilidad y la aplicación que se desea hallar en é ${ }^{49}$.

Por su parte, Francisco Cabarrús, economista, hombre de negocios, pensador y escritor ilustrado, empieza por hacer una propuesta que en aquellos tiempos era poco menos que una utopía:

47 Ibidem, pág. 89.

48 Ibidem, pág. 92

49 Ibidem, págs. 93-94. 
Haya, pues, en cada lugar una o más escuelas, según su población, destinada a enseñar a los niños a leer, escribir, contar, los primeros elementos de la geometría práctica y un catecismo político en que se comprendan los elementos de la sociedad en que viven y los beneficios que reciben de ella. En cuanto a leer, escribir, contar y los elementos de geometría práctica, hay métodos más o menos sencillos y útiles, como vr. gr. le Bureau Tipografique; cualquiera sería preferible a nuestras cartillas, que deberían suprimirse ${ }^{50}$.

El autor plantea como alternativa al clásico catecismo religioso un catecismo político:

La constitución del estado, los derechos y obligaciones del ciudadano, la definición de las leyes, la utilidad de su observancia, los perjuicios de su quebrantamiento: tributos, derechos, monedas, caminos, comercio, industria; todo esto se puede y debe comprender en un librito del tamaño de nuestro catecismo por un método sencillo, que cierra el paso a todos los errores contrarios. Se nos inculcan en la niñez los dogmas abstractos de la teología, ¿y no se nos podrían enseñar los principios sociales, los elementos de la legislación y demostrar el interés común e individual que nos reúne? ${ }^{51}$

Para el ilustrado hispano-francés la educación elemental es un derecho y un deber:

Esta enseñanza elemental y tan fácil ha de ser por consiguiente común a todos los ciudadanos: grandes, pequeños, ricos y pobres; deben recibirla igual y simultáneamente. ¿No van todos a la Iglesia? ¿Por qué no irían a este templo patriótico? ¿y qué son éstas ante la imagen de la patria? Por descontado en ambas partes, se acostumbrarán a la virtud, y acaso, ¿pueden existir las que la religión previene sin las que la patria necesita?, o por mejor decir, ¿la religión hace más que santificar las virtudes de hombre y de ciudadano $?^{52}$

Por lo que se refiere al tema de los maestros, nuestro autor se plantea la cuestión siguiente, ya clásica en la historia de las ideas pedagógicas modernas: « ¿Y dónde encontraremos los maestros?» Su respuesta es contundente:

50 Francisco Cabarrús, Cartas. Estudio preliminar de J.A. Maravall, Madrid, Castellote Editor, 1973.

51 Ibidem.

$52 \quad$ Ibidem, pág. 129. 
En todas partes donde haya un hombre sensato, honrado y que tenga humanidad y patriotismo. Si los métodos de enseñanza son buenos, se necesita saber muy poco para éste, que de suyo es tan fácil. Pero sobre todo, exclúyase de esta importante función todo cuerpo y todo instituto religioso. La enseñanza de la religión corresponde a la iglesia, al cura, y cuando más a los padres, pero la educación nacional es puramente humana y seglar, y seglares han de administrarla. ¡Oh, amigo mío!, no sé si el pecho de vmd. participa de la indignación vigorosa del mío, al ver estos rebaños de muchachos conducidos en nuestras calles por un esculapio armado de su caña. Es muy humildito el niño, dicen, cuando quieren elogiar a alguno. Esto significa que ya ha contraído el abatimiento, la poquedad, o si se quiere, la tétrica hipocresía monacal. ¿Tratamos por ventura de encerrar la nación en claustros y de marchitar estas dulces y encantadores flores de la especie humana?

Aquella edad necesita del amor y de las entrañas de padre, ¿y la confiamos a los que juraron no serlo? Necesita de la alegría y de la indulgencia, ¿y la confiamos a un esclavo o a un déspota? ¡Por qué extraño trastorno de todos los principios han usurpado así sucesivamente las más preciosas funciones de la sociedad tantos institutos fundados en la separación y abnegación de ella! ${ }^{53}$

Por el contrario, el maestro que plantea Cabarrús debería ser:

el mejor padre y el mejor marido: debería este empleo tener en el ayuntamiento y en todos los actos públicos un asiento distinguido: debería dotarse competentemente, ¿y por qué la gratitud pública no había de conservar la memoria de aquellos que la desempeñasen mejor? El arte sublime de formar hombres ¿no equivaldría a la ciencia funesta y fácil de destruirlos o degradarlos ${ }^{54}$

\section{La maestra de la Ilustración española}

No podemos encontrar un camino paralelo de preocupación por la maestra de escuela en el siglo XVIII semejante al que se llevó a cabo con los maestros. Aunque, como veremos, se avanzó bastante, especialmente sobre el papel, en los proyectos dados a conocer, y aumentó el número de partidarios de considerar la formación de las maestras, así como de escolarizar a las niñas a la par que se hacía con los niños, aún debería pasar bastante tiempo antes de que se produjeran avances significativos en tales ámbitos.

$53 \quad$ Ibidem, pág. 131.

54 Ibidem. 
De hecho, en el siglo XVIII empieza a aparecer la instructora, más que maestra de niñas, siguiendo el modelo educativo ilustrado centrado en poner la enseñanza profesional de las niñas y mujeres al servicio del desarrollo económico. En cualquier caso, hay que interpretar como un paso adelante la aparición en agosto de 1768 de las normas para el establecimiento de casas destinadas a la educación de niños y niñas ${ }^{55}$. Se considera conveniente que la educación de la juventud «no se limite sólo a los varones; las niñas tienen que ir a la escuela pública, espacio donde se empaparán de esa moral y buenas costumbres que impregnarán sus hogares». Estaba previsto que las personas encargadas de la educación de las niñas debían ser:

matronas honestas e instruidas, idóneas para cuidar de su formación y cultivar en ellas los principios y obligaciones de la vida civil y cristiana y las habilidades propias de su sexo. Parece que la educación de la mujer interesó como medio para preservar la moral pública, cuyo control, en el Antiguo Régimen, estaba en manos de la Iglesia ${ }^{56}$.

Hacia finales de la década de los setenta, Carlos III comenzó a impulsar la creación de las Diputaciones de Caridad, instituciones de carácter vecinal que tenían por misión establecer escuelas y entidades caritativas en los barrios. Por Real Cédula de 11 de junio de 1783 se establecían oficialmente las escuelas de niñas en España. Las escuelas públicas, o casas destinadas a la educación de las niñas, iban a contar con el respaldo económico de las Diputaciones de Caridad.

Las Diputaciones de Barrio de Madrid examinaban a las maestras de su «habilidad, suficiencia, buen porte», conducta y capacidad para gobernar con acierto su escuela. Las candidatas tenían que presentar a las diputaciones un memorial informando de su habilidad y costumbres, después estos centros sometían a la maestra a una prueba de habilidad para asegurarse de que sabían coser y conocían el catecismo. En cualquier caso, «se preferirá siempre a las de mejores costumbres en concurso de igual habilidad ${ }^{57}$.

La Real Cédula de 11 de mayo de 1783, fecha en que se establecían oficialmente las escuelas de niñas en el país, supuso el primer reconocimiento legal de la necesidad de alfabetizar a las mujeres para lograr la uniformización de la cultura a escala nacional y propiciar el desarrollo económico. Las exigencias

$55 \quad$ La fecha de aparición de esta norma fue la de 14 de agosto de 1768.

56 Véase Sonsoles SAN Román, Las primeras maestras, op. cit., pág. 56.

57 Ibidem, pág. 57. 
de productividad eran un criterio prioritario. En julio de 1778 se prohíbe la introducción en España de gorros, guantes, calceta, fajas de lino, cáñamo, lana o algodón. En 1779, la prohibición se amplía a todo género de utensilios, ropas y muebles. Con ello se deja en manos de las Sociedades Económicas el trabajo de promover las correspondientes industrias nacionales. Una de las principales labores de estas Sociedades fue resaltar el valor de la mujer como recurso humano en la producción textil para crear riqueza, ofrecer en consecuencia puestos de trabajo y evitar limosnas y caridades. Para las escuelas de barrio donde asistían las niñas, creadas por el monarca en 1783, que se abrieron en Madrid con «trascendencia a todo el reino» ${ }^{58}$ siguiendo el ejemplo de la existente en el barrio de Mira el Río, se fijaban las enseñanzas que debían recibir las niñas: lectura, catecismo y labores comunes. Estas cuidadoras de niñas, procedentes de estratos sociales desfavorecidos y portadoras de escasos conocimientos, debían enseñar a las niñas comportamientos dignos y alejarlas del mal vivir; su misión era maternal y moral, pero, desde luego, no intelectual, pues el acceso a la cultura era un terreno que continuaba vedado a la mujer.

Los conocimientos que debían enseñar a sus alumnas y, por lo tanto, les eran exigidos en el examen, se enmarcan dentro de la finalidad ilustrada de hacer buenas amas de casa y amantes esposas, aunque con la novedad de que se introducen todo género de labores para potenciar su aplicación en la industria textil. Lo primero que enseñaban las maestras a las niñas eran las oraciones de la Iglesia, la doctrina cristiana por el método del catecismo, las máximas de pudor y buenas costumbres; su obligación era cuidar de que las pequeñas estuviesen limpias y aseadas en la escuela, y de que permanecieran allí con modestia y quietud:

Todo el tiempo que estén en la escuela se han de ocupar de sus labores; empezando por las más fáciles, como faja, calceta, punto de red, dechado, dobladillo, costura; siguiendo después a coser más fino, bordar, hacer encajes; y en otros ratos que acomodará la maestra según su inteligencia, a hacer cofias o redecillas, sus borlas, bolsillos y sus diferentes puntos, cintas caseras de hilo, de hilaza, de seda, galón, cinta de cofias, y todo género de listonería, o aquella parte de estas labores que sea posible, o a que se inclinen respectivamente las discípulas; cuidando la ayudanta de una porción de ellas, que pueden ser las menos aprovechadas ${ }^{59}$.

Respecto a la formación de las maestras nos han llegado menos noticias, aunque se sabe que se les exigía menor preparación que a los maestros:

\footnotetext{
$58 \quad$ Ibidem, pág. 59.

59 Ibidem, págs. 60-61.
} 
También había maestras, pero muy pocas y con un carácter y un estatus marcadamente inferior al de los maestros. Salvo excepciones, no sabían leer ni escribir; entre otras razones, porque ni siquiera habían ido de pequeñas, o de mayores, a la escuela (...). Sabían el Catecismo religioso, y muchas veces no entero, y lo que enseñaban comúnmente a sus discípulas eran las principales oraciones de la religión católica, la costumbre de prácticas piadosas y en bastantes casos, a coser y bordar. Es decir, había una barrera descomunal entre el mundo del niño y el de la niña, del maestro y de la maestra. A tales maestras se les pagaba mucho menos que a los maestros, aunque se las vigilaba casi más que a ellos, pues la sociedad estaba muy preocupada por la gran categoría moral que en su concepto debería tener la maestra ${ }^{60}$.

A la maestra analfabeta se le encomendó la tarea de reproducir ese ideal de cultura femenina que aseguraba la educación hogareña de las niñas de las clases más desfavorecidas. La responsabilidad de la maestra analfabeta era inculcar a las niñas la subordinación y la dependencia exigidas a la mujer. La maestra analfabeta permitió dar respuesta a las necesidades culturales, industriales y económicas por las que atravesaba nuestro país. Las niñas de finales del siglo XVIII aprenden a rezar y a coser. Así, entre sus primeros cometidos estaba el de imponer a las niñas socialmente desfavorecidas los patrones de la clase media para conseguir una rígida conducta moral, acorde con los usos y creencias religiosos del momento ${ }^{61}$.

Por su parte, como se sabe, las Sociedades Económicas de Amigos del País, promovidas especialmente por Campomanes, recibieron el apoyo incondicional de numerosos ilustrados. Realizaron múltiples actividades encaminadas a hacer posible el ideario ilustrado y concretamente crearon instituciones educativas de carácter profesional sobre todo para niñas y en número menor también para niños. La Sociedad Económica Matritense es la más importante no sólo por ser una de las primeras en crearse y porque recibe un mayor apoyo por parte de los hombres públicos de renombre, sino también porque servirá de modelo a las restantes.

En 1776 la Sociedad Económica Matritense abre cuatro escuelas patrióticas en barrios de Madrid: San Ginés, San Sebastián, San Martín y San Andrés, todas ellas están destinadas únicamente a niñas. Su principal finalidad era enseñar a hilar el cáñamo, el lino, el algodón y la lana, pero posteriormente se ocuparon también de otras labores más rentables, como la costura, la calceta y el bordado.

\footnotetext{
60 Véase Julio RuIz, art. cit., pág. 229.

61 Más datos en Sonsoles San Román, op. cit., págs. 60 y ss.
} 
Según las primeras normativas convenía que las maestras supieran leer, escribir y contar, pero algunas de ellas sólo conocían su oficio y únicamente eran examinadas de habilidades manuales y técnicas ${ }^{62}$.

En estos establecimientos se intentaba compaginar una formación útil con la inculcación de ciertas normas morales, al mismo tiempo que no se descuidaba la instrucción religiosa de las aprendizas a cargo de catequistas. Intentaban propagar su ideario ilustrado a través de las más variadas ocupaciones: publicar memorias, socorrer a enfermos, abrir escuelas, impartir clases y conferencias, conceder premios para estimular la producción en sus diferentes ramos, otorgar dotes para fomentar los matrimonios.

En el Reglamento para las maestras se explicita con claridad que:

el fin y principal objeto de este establecimiento es fomentar con trascendencia a todo el Reino la buen educación de las jóvenes en los rudimentos de la fe católica, en las reglas del bien obrar, en el ejercicio de las virtudes, y en las labores propias de su sexo dirigiendo a las niñas desde su infancia y en los primeros pasos de su inteligencia, hasta que proporcionen los medios para hacer progresos en las virtudes, el manejo de sus casas, y en las labores que les correspondan, como que es la raíz fundamental de la conservación y el aumento de la Religión y el ramo más interesante de la Policía y Gobierno económico del Estado ${ }^{63}$.

En 1791 la Junta de Damas de la Matritense, que se había hecho cargo de estas escuelas, elabora un nuevo plan de actividades para las mismas:

Se dividirá a las discípulas en tres clases: a la primera se les enseñará a hacer faja, calceta, aspar, devanar, torcer, y a leer... En la segunda se enseñará a rastrillar y a cardar, siendo preciso para que estas operaciones salgan bien, que las niñas tengan cierto pulso y destreza que difícilmente se puede hallar en las más principiantas; también se enseñará en misma clase a coser en blanco, a la española, francesa, a escribir y contar, cuyo último requisito es necesario para la clase de tejidos. En la tercera y última clase, se enseñará a tejer, cintas, lienzos, mantelería y cotonería en las tres escuelas — San Ginés, San Sebastián y San Martín— y en la de San Andrés estameñas, fajas y ligas ${ }^{64}$.

62 Véase el detenido estudio que acerca de tales escuelas realizamos en nuestro libro: Educación popular en la España de la segunda mitad del siglo XVII, op. cit., especialmente capítulos III y IV, págs. 157 y ss.

63 Véase Olegario NEgrín, Ilustración y educación. La Sociedad Económica Matritense, Madrid, Editora Nacional, 1984, págs. 105 y ss.

64 Ibidem, págs. 107-108. 
Este plan de actividades que intenta incorporar a las escuelas las primeras letras no llegará a realizarse en toda su amplitud porque, a pesar de que en 1792 la Matritense aprueba el nombramiento de un maestro de primeras letras para las cuatro escuelas patrióticas, en realidad solamente se dedicará a un número reducido de niñas: aquéllas que por edad, antigüedad y talento reunían las cualidades adecuadas para recibir estos primeros conocimientos.

\section{El maestro eclesiástico}

La historiografía tradicional ${ }^{65}$ considera a José de Calasanz el creador de la escuela popular moderna; se entiende desde esa perspectiva que mientras los jesuitas se ocupan más directamente de la enseñanza secundaria, reformándola a través de la Ratio Studiorum, los escolapios se centran en la educación del pueblo, partiendo de la reorganización de este tipo de enseñanza con un nuevo plan de estudios. La escuela popular calasancia se caracteriza por ser gratuita y pensada para el pueblo llano.

Las Escuelas Pías nacieron en 1602, fundadas por José de Calasanz, como sociedad seglar para el sostenimiento de un colegio popular y gratuito instalado en Roma. La Congregación Paulina de las Escuelas Pías enseñaba a los niños a leer y escribir, matemáticas, gramática y retórica, caligrafía, música, latín, doctrina cristiana y una rudimentaria formación profesional para que los muchachos pudieran acceder a un empleo y ganarse la vida. En España, tras algunos intentos fallidos se abre el primer colegio de escolapios en Barbastro, en 1677, aunque habrá que esperar algunos años más para que se difundan y consoliden las Escuelas Pías en nuestro país.

Durante el siglo XVIII se produjo la expansión escolapia en la península abriendo múltiples centros escolares en poblaciones secundarias y en pueblos pequeños así como en poblaciones más importantes. Los nuevos centros gozaron de aprobación eclesiástica y por la autoridad civil y siguieron las directrices educativas y religiosas diseñadas con anterioridad por el fundador y las que fueron surgiendo con posterioridad. Durante todo el siglo XVIII la enseñanza escolapia siguió siendo gratuita, incluyendo el material escolar:

65 Véanse, entre otras publicaciones, las siguientes: Valentín CabaLLERo, Orientaciones pedagógicas de San José de Calasanz, Madrid, CSIC, 1945; Severino Giner, San José de Calasanz, maestro y fundador, Madrid, BAC, 1992; Ángeles GALino, «San José de Calasanz creador de la escuela popular», Revista Española de Pedagogía, 26, 1949, págs. 325-369; Antonio José Onieva, «San José de Calasanz, fundador de la escuela popular», Revista Española de Pedagogía, 10, 1948, págs. 18-20. 
He resuelto, satisfecha la deuda, que ha sido preciso contraer para abrir las muestras de letras e imprimir los libros pertenecientes al total del método, se invierta lo poco o mucho que den de sí muestras o libros, en beneficio de los mismos niños pobres, para comprarles papel, plumas y los libros necesarios ${ }^{66}$.

Los colegios de escolapios serán instituciones educativas esenciales para España en el periodo que estudiamos ya que desarrollan un significativo proyecto de escolarización y alfabetización, sus escuelas para niños pobres se convertirán en modelo pionero de la escuela popular: gratuita, graduada y estable, defendiendo el derecho del pobre a la educación y ofreciendo una enseñanza primaria, media y profesional, no como escuela asistencial de marginados sino como alternativa de promoción para la gran masa de clases menesterosas del momento ${ }^{67}$.

Los escolapios, en concreto, se limitaban al adoctrinamiento de los niños pobres y evitaban especialmente los roces con los jesuitas. Pero poco a poco se van asentando en ciudades y villas en donde generalmente no existen otras órdenes religiosas dedicadas a la instrucción de la juventud. Este intento de extender sus actividades educativas dio lugar a fricciones con los maestros pagados por los ayuntamientos. Para justificar su expansión los escolapios hacen una singular interpretación de sus Constituciones entendiendo que si bien deben dedicarse al adoctrinamiento de los niños pobres ellos no indica que no puedan instruir a los niños ricos.

Las relaciones entre jesuitas y escolapios y, especialmente, la situación de estos últimos en el panorama ilustrado, han sido analizadas por J. Varela y F. Álvarez-Uría:

A partir de la expulsión de los jesuitas no sólo se harán cargo los discípulos de San José de Calasanz de alguno de los colegios de la Compañía, sino que además adquirirán una posición más sólida en el ámbito de la primera enseñanza. Es preciso, no obstante, señalar que aunque sus estudiosos sitúan su edad de oro entre los años 1750 y 1805, carecen prácticamente durante este período de nuevas fundaciones, a pesar de la solicitud que hicieron muchos pueblos (...) ¿De dónde

${ }_{66}$ Felipe Scio, F., Método uniforme para las Escuelas de Cartilla, deletrear, leer, escribir, aritmética, gramática castellana, y exercicio de doctrina cristiana, como se practica por los Padres de las Escuelas Pías, Madrid, Imprenta de Pedro Marín, 1780, pág. V.

67 Las Constituciones ordenaban seguir el breve Ad ea de Paulo V de 6 de marzo de 1617 por el que se establecía que los escolapios trabajarán, se esforzarán y se comprometerán a enseñar a los niños los primeros rudimentos, la gramática, el cálculo y, sobre todo, los principios de la fe católica, e imbuirlos en las buena y sanas costumbres y en educarlos cristianamente gratis, sin sueldo, sin paga, sin salario ni honorario. 
les viene, pues, a los calasancios esa posición especial? La expulsión de los jesuitas les favoreció, pero sin duda tienen más importancia otros factores: haber aceptado el regalismo hasta el punto de que se pusieron a disposición del Rey y de Floridablanca para que, si lo consideraban oportuno, convirtiesen sus colegios en escuelas públicas; contar con un sistema uniforme de enseñanza ${ }^{68}$, obra del P. Felipe Scío, uno de sus miembros más destacados; disponer de un cuerpo de maestros ya formado; haber fijado un tipo de letra, lo que constituía un problema candente en la época, la escolapia o bastarda, llamada más tarde española; contribuir a enseñar el castellano en todas sus clases a partir de la promulgación de una Real Cédula de Carlos III de 1768; y, por último, porque sus prácticas educativas de domesticación se avenían bien a los deseos del gobierno ilustrado, si se aplicaban a ciudadanos de segunda categoría ${ }^{69}$.

Algunos principios fundamentales del ideario educativo calasancio que se van consolidando a través de la historia y que ya se aplicaban en el siglo ilustrado son:

- La educación impartida ha de ser completa, integrando las letras y ciencias con la doctrina y piedad cristianas, siendo ésta última prioritaria.

—En el ministerio educativo hay que atender principalmente a los pobres y a los niños desde los primeros años.

- La enseñanza ha de preparar para la vida, incluyendo humanidades pero también ciencias o matemáticas y habilidades prácticas (caligrafía, música).

—El método didáctico ha de ser breve, sencillo y eficaz para que los niños aprendan en poco tiempo.

- La escuela debe ser graduada y ha de constar, al menos, de cuatro grados en la enseñanza elemental y de otros cuatro para las humanidades y ciencias.

$68 \quad$ El Método uniforme para las escuelas (1780) responde a dos intenciones: recoger la tradición y el buen hacer de la orden en el terreno de la enseñanza de primeras letras, y darle una formulación precisa y estable, que se concretaría en el establecimiento y la adopción de un «método sólido, fácil y uniforme. Estas intenciones responden a las preocupaciones de la Ilustración española por reformar la enseñanza manteniendo lo valioso de la tradición nacional e introduciendo mejoras conducentes sobre todo a acrecentar la eficacia en la instrucción. (...) Se trata, pues, de un breve, prescriptivo y enjundioso tratado de pedagogía de la enseñanza elemental en el que se dan instrucciones obligatorias para las Escuelas Pías de la provincia de Castilla, el llamado Método uniforme, cuyos objetivos, según el prólogo, se formulan así: "La piedad y religión, la urbanidad y crianza política y las letras proporcionadas a la edad de los niños y las circunstancias de cada uno". Es decir, una formación de tipo religioso y de carácter a un tiempo, intelectual y moral —la piedad—; y una formación de tipo humano, compuesta por un elemento de carácter moral — la urbanidad o crianza - y por otro de cariz intelectual — las letras. Se regula toda la conducta del alumno desde que se levanta hasta que se acuesta, en el hogar, en la sociedad y en la escuela». Recogido de la página web de la institución calasancia: wwww.escolapios.es

69 Véase Julia Varela y Fernando Álvarez-Uría, Arqueología de la escuela, Madrid, Ediciones La Piqueta, 1991, págs. 160 y ss. 
Cada alumno pasa individualmente al grado superior cuando esté preparado para ello.

- Todas las escuelas pías tienen un plan educativo común. Pero cada una de ellas tendrá las estructuras educativas adecuadas, según las circunstancias, y un reglamento propio que determinará las funciones diversas y las obligaciones de los alumnos, maestros, directivos, padres de familia, autoridades civiles, etc. ${ }^{70}$

Los escolapios aportan además una buena organización de las enseñanzas: tres clases en Primaria, cinco en Secundaria, más tarde ampliada a seis y ocho. Las clases no se ordenan por edades, sino por niveles de conocimiento, siendo muy flexible la promoción de nivel. La programación de cada clase estaba perfectamente determinada en sus contenidos, sus métodos e incluso con sus libros de texto. Todo el plan era general para la Orden, aunque cada colegio lo podía adaptar con flexibilidad a su modo y circunstancias particulares. Características generales eran la seriedad y eficacia de la enseñanza y el carácter preventivo de la educación. Bastantes estados europeos adaptaron más adelante numerosos elementos de esta organización escolar. En el aspecto económico las Escuelas Pías eran fieles al principio de gratuidad de sus establecimientos. La financiación la buscan a través de fundaciones, aportaciones de príncipes y municipios y culto de sus iglesias.

De lo dicho hasta aquí se puede deducir que los maestros escolapios estaban mejor preparados que los miembros docentes de la Hermandad de San Casiano para adaptarse a los nuevos criterios ilustrados. Los discípulos de Calasanz, no sólo poseían un método uniforme de enseñanza, un tipo de letra, libros de enseñanza y un sistema pedagógico propio que respondía mejor a las preocupaciones en este terreno de los políticos del momento que el que ofrecían los maestros agremiados, sino que, además, se adhirieron al poder real, hasta el punto de que algunos hermanos de Castilla pidieron la independencia de Roma. Pero, para los ilustrados más influenciados por las corrientes europeas de separación de poderes y laicismo, la educación fundada en el temor de Dios y en la obediencia a sus representantes no era la más adecuada a los intereses del Estado, como hemos visto era el pensamiento explícito de Francisco Cabarrús ${ }^{71}$.

A pesar de las alabanzas que el Manual literario dedica a los escolapios en 1785: «La Religión de las Escuelas Pías, que por voto solemne, consagra todos sus laboriosos afanes y desvelos a beneficio de la República, en la enseñanza gratuita de la juventud ${ }^{72}$, parece evidente que los ilustrados preferían el sistema

70 Recogido de la página web citada de la institución calasancia: wwww.escolapios.es

${ }^{71}$ Vid., especialmente, el texto que lleva el número de cita 51.

72 Memorial Literario Instructivo y Curioso de la Corte de Madrid, septiembre de 1785. Véase también las alabanzas que aparecen en El Duende de Madrid, Discurso IV, citado por Carmen Labrador, y Juan Carlos de Pablos, op. cit., págs. 162 y ss. 
pestalozziano. Pero, después de la corta experiencia del Instituto Pestalozziano, será la escuela escolapia la que de nuevo se imponga con el retorno de Fernando VII llegando a convertirse en modelo para la escuela nacional. El influjo de los escolapios será bastante considerable en el Plan y Reglamento de Primeras Letras de 1825 y en el Reglamento de 1838, que tendrán un papel relevante en el ámbito educativo durante todo el siglo XIX ${ }^{73}$.

\section{Los educadores de los niños nobles y ricos}

Los hijos de la aristocracia y la burguesía más acomodada no asistían ni a la escuela pública ni a la impartida por los eclesiásticos, sino que recibían la asistencia educativa en sus propias casas. Se trata de la enseñanza que, a veces, se denomina doméstica, impartida por educadores diferentes que van desde leccionistas, más o menos aficionados, a preceptores de auténtica calidad y valía seleccionados por sus padres entre miembros del clero, escritores, profesores de universidad y de segunda enseñanza y aquellos maestros preparados de la época. Según las posibilidades económicas de cada familia, se solía tener en casa un ayo, que era más bien una especie de acompañante, controlador y colaborador de los muchachos en su formación, y un preceptor que era el verdadero educador. A veces, ambas figuran quedaban fusionadas en una sola bien por economizar, bien, en algunos casos, porque se entendía que de esta manera se controlaba mejor a los niños.

Sin embargo, ya en aquella época fue una enseñanza muy criticada. Veamos a continuación un ejemplo de los peligros de este tipo de enseñanza sacado de El Personero ${ }^{74}$, el periódico publicado en la década de los años sesenta del siglo XVIII por el canario Clavijo y Fajardo ${ }^{75}$.

\footnotetext{
73 Véanse a este respecto los artículos de Julio Ruız citados anteriormente: «La educación del pueblo español en el proyecto de los Ilustrados» y «La crisis del profesor español en la Ilustración».

74 José Clavijo, El Pensador, Madrid, Ibarra, 1762. Nosotros hemos manejado en la Biblioteca Nacional de Madrid la primera edición impresa por Joaquín Ibarra. En el tomo 1. ${ }^{\circ}$, de 1762, Clavijo se firma como Joseph Álvarez y Valladares; a partir del tomo $2 .^{\circ}$ aparece el verdadero nombre del autor; los tomos $2 .^{\circ}, 3 .^{\circ}$ y $4 .^{\circ}$ llevan fecha de 1763; el tomo $5 .^{\circ}$ se publicó en 1764; el tomo $6 .^{\circ}$ en 1767 . Hay una edición reciente de la obra publicada en 1999, con un estudio introductorio de Yolanda Arencibia, por la Universidad de Las Palmas y el Cabildo Insular de Lanzarote. Datos biográficos e información acerca de su pensamiento educativo se pueden encontrar en Olegario Negrín, Historia de la educación en España, op. cit., págs. 151-160.

75 Más datos sobre Clavijo y Fajardo en nuestros trabajos siguientes: «Locke y Rousseau en El Pensador de Clavijo y Fajardo», en Estudios dieciochistas. Homenaje al profesor José Miguel Caso González. Oviedo, Instituto Feijoo de Estudios del Siglo XVIII, 1995, vol. II, págs. 181-194; «Ilustración, educación y ciencias naturales en Clavijo y Fajardo», en V Jornadas de Estudios sobre Fuerteventura y Lanzarote, Puerto del Rosario, Cabildos Insulares de Fuerteventura y Lanzarote, 1993, vol. II, págs. 443-468; «Clavijo y Fajardo, naturalista
} 
Se supone que alguien, de forma anónima, escribe a Clavijo contándole su experiencia personal:

Nací de padres ilustres, y ricos, y sin tener con quien repartir sus bienes, ni su cariño. Si esta fue dicha, o desgracia, júzguelo quien sepa graduar el valor de las cosas, sin gobernarse por la apariencia, y conozca cómo se suele tratar a un hijo, en quien están depositadas todas las esperanzas de perpetuar el nombre, las glorias, y las riquezas de una casa. Paso en silencio los primeros años de mi vida, en que los desvelos, las contemplaciones, y las alabanzas necias, que pródigamente se daban a mis caprichos, me robaron el tiempo y la atención, desde que principié a obrar por instinto, hasta que las primeras luces de la razón empezaron a rayar en mi alma; y sólo diré que, cuando estas llegaron, me encontraron ya muy contento con mi existencia, muy preciado de persona, vano, soberbio, audaz, y preocupado de que mi vida era muy importante, y mi naturaleza muy superior a la de todos los que me rodeaban. Así los trataba, en cuanto permitía mi edad, con altivez y aún con desprecio; y se pronosticó desde entonces, que sería hombre de provecho algún día.

Desde la alegre vida de hacer rabiar al Aya, y las Doncellas, me vi obligado a pasar a la molesta sujeción de un Ayo. Mis padres, que llegaron a echar menos este artículo en la lista de los muebles precisos a su fausto, y dignidad, pensaron en ponérmelo, con el fin, a lo que ahora entiendo, de que me acompañase cuando salía, y los libertarse de la pensión de sufrirme cuando estaba en casa; y pensaron también, contra su costumbre, en tratar este asunto con economía, dándome un Ayo, que al mismo tiempo fuese mi Preceptor ${ }^{76}$.

Aunque los padres estaban bien asesorados, finalmente la madre eligió al ayo que tenían más a mano y que resultó el más inadecuado:

Algunos parientes, y amigos de mi padre, hombres cuerdos, y bastante ilustrados para conocer toda la importancia de una buena elección, le hicieron ver cuanto convendría buscar un hombre maduro, aplicado, de presencia agradable, que hubiese vivido entre el tumulto del mundo lo suficiente para conocerlo, y no demasiado para haber contraído su corrupción: que tuviese el juicio recto, el discernimiento justo, y el espíritu libre de preocupaciones; y que a una alma firme, juntase un humor igual, unas costumbres suaves, el talento de persuadir, y a lo menos los primeros elementos de las facultades, que convenían a mi calidad: añadiendo, que

ilustrado», en XI Coloquio de Historia Canario-Americana, Las Palmas de Gran Canaria, Ediciones del Cabildo Insular de Gran Canaria, 1996, págs. 679-701.

76 Tomo V, pensamiento LXIII, págs. 184 y ss. de El Pensador. 
si se hallase un hombre con todas esas circunstancias, que no era muy fácil, no se detuviese en el estado, o profesión del sujeto: Todo esto, y mucho más, he sabido que dijeron a mi padre, quien sin duda hubiera tomado el consejo, porque, aunque hombre de cortas luces, tenía docilidad, y me amaba; pero quiso mi desgracia que mi madre, que a pesar de un bello talento, y de un corazón admirable, tenía una debilidad de juzgar resolutivamente en ciertas materias, que no eran de su competencia, había puesto la mirada en un hijo de un criado mayor suyo, el cual se había paseado por las inmediaciones de cierta Universidad: tenía una catadura fea, y un gesto regañón; y a más de esto, debía ser barato; y no fue menester más para dármelo por Ayo, en fuerza de estas prendas, y títulos de suficiencia tan revelantes ${ }^{77}$.

El razonamiento del informante no admite dudas acerca de las verdaderas razones por las que los padres elegían el ayo de sus hijos:

Es muy notable, y digno de compasión, que un padre, que no perdona gasto alguno para procurar a sus hijos establecimientos brillantes, y que a costa de gastos excesivos les mantiene magníficos vestidos, y equipajes, y multitud de criados inútiles, sólo conozca la economía cuando se trata de buscar, y atraer una, o más personas, que cultiven el espíritu de los mismos hijos, los instruyan en la Religión, planten en sus corazones las semillas del sano Moral, y de la buena política, los inclinen a cosas virtuosas, y útiles, y cubran su más vergonzosa desnudez; esto es, sus defectos naturales, sus malas inclinaciones, y su ignorancia. Pero ello es, que se encuentran padres de este temple: que son muchos los que se encuentran; y que su conducta es prueba evidente de que aquellos gastos se sacrifican al orgullo, y la vanidad, sin tener parte en ellos el sincero deseo de hacer bien a sus hijos. No pretendo con ésta, ni otras reflexiones hacer odiosos a unos padres, cuya memoria me será siempre respetable. Quizá fue falta de conocimiento, y acaso era etiqueta del tiempo en que nacíi ${ }^{78}$.

¿Cómo actuaba el nuevo maestro? ¿Cuáles eran sus características formativas? Como veremos, en la experiencia práctica del informante, más bien hay que hablar de defectos que de virtudes:

Púsome en consternación el nuevo estado, porque llegué a creerme entre las garras de una fiera, en quien, lejos de esperar la menor blandura, temía un rigor continuo, sin mezcla de piedad. Mi primera diligencia fue fondear el carácter de mi

77 Ibidem, págs. 187-189.

78 Ibidem, págs. 189-191. 
Ayo. No quiero decir en esto, que hubiese en mi capacidad, ni reflexión bastantes para hacer con éxito esta observación; pero había malicia, curiosidad, y deseos de conocer los flacos, y debilidades de mi Ayo, para saber cómo había de gobernarme con él, y lo que podría prometerme. A poco tiempo salí de este cuidado. Mi buen Ayo tenía no una, sino muchas fragilidades, y no supo reprimirse, como debía, a fin de ocultármelas. Descubrí, pues, que era tímido, interesado, ignorante, caprichoso, y adulador, y sobre todo que contaba con mi intercesión para acomodar algunos parienticos, y acudir a otras obras piadosas. Sobre este conocimiento fundé mis alegres esperanzas de tener en él un criado de mayor autoridad, que contentase mis caprichos, en vez de un Censor rígido de mi conducta, y un Maestro ilustrado, y celoso de mi bien ${ }^{79}$.

Ante el panorama que estamos viendo, utilizando los argumentos que aparecen expuestos en El Espectador, al menos queda la esperanza que el discípulo pudiera aprender algo de su profesor particular:

Yo no me criaba para subir a las Cátedras, según él decía, y así era conveniente dejar las tareas del estudio a los que habían de vivir de este afán. Contentose, en fuerza de este razonamiento, con enseñarme unos malos principios de Gramática, y de Philosophia Aristotélica: pusome en la mano un mal compendio de Historia, los libros de Año Virgineo, la Corte Santa, y el grande Hijo de David, y me dijo, que en ellos encontraría mucho más de lo preciso para vivir con lucimiento en mi clase. Dábame con frecuencia, aunque a costa de mi dinero, buenas lecciones de cacho, rebesino, y malilla, a que mi Ayo era muy aficionado, y llegué a hacer en esto progresos admirables. En una palabra, enseñome lo que sabía, y no lo que ignoraba, porque esto era imposible. Así no supe, ni Lenguas vivas, ni muertas, ni Philosophia, ni Música, ni Poesía, ni Dibujo, ni Historia, ni Mathemáticas, y ni aún el Cathecismo; pero en cambio de todo esto salí excelente tahúr ${ }^{80}$.

Sin embargo, en la carta siguiente se reconoce que no todos los ayos eran iguales al descrito sino que había también educadores domésticos de calidad:

Solía irme a pasear muchas tardes con un parientito mío, que también llevaba su Ayo; ipero qué Ayo! ¿Qué carácter, qué juicio, qué prudencia y discreción de hombre! Yo hacía el cotejo en estos paseos, y en ellos acababa mi Ayo de perder su poca opinión. Veía que aquel trataba a su pupilo con grande afabilidad, y cariño:

79 Ibidem, págs. 191-192.

80 Ibidem, págs. 192-194. 
que cuando sus deseos eran inocentes, entraba en ellos con tanto gusto, aunque repugnasen tal vez a su genio, como si el mismo los hubiese excitado, y que solía anticiparse a ellos cuando estaba satisfecho de su conducta. En su gesto, en sus palabras, y acciones se leían el cariño, y la amistad, aquella amistad ilustrada, y decente, que depende de la razón, y se mantiene siempre con dignidad: que a pesar de una disciplina severa, y de una escrupulosa exactitud a no dejar sin castigo cosa alguna, que lo mereciese, parecía que empleaba más su autoridad para hacerse amar, que para corregir: que en sus correcciones no entraba jamás a la parte el mal humor, la cólera, ni la aspereza: que si le imponía algún castigo, era haciendo ver que le esforzaba a ello, y manifestando sentimiento de verse reducido a aquella dura necesidad: que no se paraba en menudencias frívolas, haciendo semblante de no verlas: que sus lecciones eran indirectas, mostrándole en los defectos ajenos a los suyos propios, y dejándole a el mismo la aplicación; y finalmente, que le trataba como a hombre, para que llegase a serlo... ${ }^{81}$

Ya en la época se consideraba esta enseñanza mal pagada y con escasa valoración real ${ }^{82}$. Por parte de este tipo de maestros existía también una preocupación creciente por mejorar su situación económica y su prestigio social; en la prensa de la época es posible encontrar testimonios del mal trato social que decían recibir algunos preceptores que manifestaban que se sentían poco valorados, que carecían de instrumentos de enseñanza adecuados y que cualquier persona se consideraba preparada para hablar de educación sin estarlo, al tiempo que denunciaban públicamente lo mal pagado que se encontraban ${ }^{83}$. Sin embargo, se pueden encontrar también testimonios de padres preocupados por la buena educación de sus hijos que estaban dispuestos a sacrificarse económicamente para conseguir un buen profesional de la enseñanza, como el de un padre que, refiriéndose al preceptor de su hijo, afirma: «Él se puso el precio y a fe de hombre de bien, que todo cuanto tengo y valgo le hubiera yo dado de muy buena gana» ${ }^{84}$.

No obstante, aunque de una forma muy lenta, se van logrando ciertos progresos en las condiciones de estos docentes, tanto en el aspecto profesional, como en el económico y social. Pero se seguirá manteniendo una diferencia entre lo que establecen las normas y la realidad particular de cada maestro. Será necesario que transcurra mucho tiempo aún para que se llegue a una mayor dignificación de la profesión docente, realidad a la cual se va tendiendo, de forma progresiva, en la primera mitad del siglo XIX.

\footnotetext{
81 Pensamiento XLIV, págs. 212-214.

82 Vid. El Discurso sobre Educación, publicado el 29 de mayo de 1789 en el Correo de Madrid.

83 El Correo de Madrid, 28 de julio de 1790.

84 El Correo de Madrid, 6 de junio de 1789.
} 


\section{Conclusiones}

Podría bastar con mencionar que personas de la talla intelectual de Feijoo, Jovellanos, Cabarrús y Olavide, y políticos ilustrados como Floridablanca, Aranda y Campomanes, por sólo citar algunos bien conocidos, están detrás del cambio de mentalidad y de práctica educativa que se pretendía, para sentirnos afortunados y esperanzados. Otra cosa bien distinta se produce en el terreno de los hechos, al comparar la distancia que existía entre lo proyectado y lo realizado.

Como han dicho algunos autores, habría hecho falta quizá una ruptura para lograr el cambio apetecido por la Ilustración española, pero la estructura social predominante y el tipo de economía de subsistencia reinante impidieron tal posibilidad. Podemos afirmar que quedó una propuesta, muchas veces no bien articulada, muchas disposiciones, muchos escritos, muchos reglamentos que buscaban un cambio y no pudieron hacerlo. Por eso se expresan los historiadores en términos de proyectismo, al referirse a esa tentativa de los ilustrados, porque los políticos interesados en el cambio no supieron hacerlo, o no quisieron hacerlo realmente, seguramente porque sobrepasaba su capacidad de renuncia a su aventajada posición social.

En el ámbito educativo, aunque fue mucho lo que se proyectó y muchos los esfuerzos realizados, los resultados no podían ser espectaculares teniendo en cuenta el déficit de punto de partida y, sobre todo, que los planes ilustrados más ambiciosos comenzaron ya en la segunda parte del siglo XVIII y se frenaron en torno a los años noventa, así que poco más de veinte o treinta años duró en sentido estricto la experiencia ilustrada.

Los dos modelos centrales de maestros que coexistieron todo el tiempo fueron el maestro formado a la usanza del Antiguo Régimen, dentro de un sistema gremial, y el maestro ilustrado formado dentro de las categorías propias del siglo dieciochista. Sin comparamos el modelo formativo del maestro antiguo y lo comparamos con el moderno, propia de la Ilustración española, los cambios son considerables tanto en los contenidos como en su didáctica, pero hay que contar siempre con la escasa tasa de alfabetización que hace que la enseñanza de las primeras letras llegue sólo a una pequeña parte de la población.

Hay que destacar la importante labor desarrollada por los maestros escolapios que, a pesar de contar con la animadversión de los ilustrados más radicales, consiguieron granjearse el apoyo de las autoridades gubernativas y crear una serie de fundaciones basadas en un sistema pedagógico uniforme, un método de enseñanza, un tipo de letra y la bibliografía de apoyo necesaria.

Si los maestros antiguos estaban poco preparados aún lo estaban menos las maestras que, por eso, algún autor las ha denominado maestras analfabetas ya 
que estaban instruidas en las labores profesionales y, en parte, en la enseñanza del catecismo, pero no así en el conocimiento de las primeras letras. Sus escuelas más que centros de formación era lugar de enseñanza profesional y acogida para niñas y muchachas populares.

Los maestros de las ciudades estaban más preparados y más controlados que los maestros rurales, con frecuencia dedicados a otros menesteres para quienes la enseñanza era una forma de ganar algún dinero más en una profesión que estaba mal considerada socialmente. Existían tribunales de exámenes, dependientes de la Hermandad de San Casiano, encargados de dar el permiso de enseñanza a cambio del pago de unos derechos de matrícula.

El modelo del magisterio ilustrado estaba representado por el maestro de primeras letras y por las maestras profesionales de las escuelas de barrio y las escuelas populares de las reales Sociedades Económicas de Amigos del País. En ambos casos no hubo tiempo suficiente para desarrollar los modelos formativos previstos. En el caso de los maestros, el movimiento reformador de San Ildefonso, en torno a la Escuela de la Real Comitiva, creada en 1788, y las ocho Escuelas Reales creadas en 1791, significó la aplicación experimental de unos criterios pedagógicos modernos tanto en los contenidos como en la metodología y en la concepción general de la enseñanza, que pronto se vería envuelto en sospecha cuando se producen los acontecimientos europeos que llevan a la Revolución francesa al centro del debate internacional.

El avance que hay que poner en el haber de los ilustrados es la incorporación paulatina de la mujer a la enseñanza tanto como profesora como alumnas; se trataba de una enseñanza limitada en los contenidos y en los principios educativos, pero, por otra parte, era el lógico reflejo de la realidad social y política española de la época.

Si hubiera que resumir en unas cuantas afirmaciones este trabajo, entendemos que las más adecuadas serían las siguientes:

—En el siglo XVIII existieron diversos tipos de maestros y educadores, seglares y religiosos, para la enseñanza de las primeras letras y la educación profesional.

-En la segunda mitad del siglo XVIII se consigue sacar en buena parte el control del magisterio de manos de los gremios.

-El siglo XVIII, en su segunda mitad, marca el comienzo de la amplia alfabetización de las niñas y muchachas y la creciente incorporación de la mujer a las tareas de maestra de escuelas.

- La política educativa ilustrada referente a los enseñantes de primeras letras se concentra en la modernización y universalización de la educación primaria y en la organización de las enseñanzas populares especialmente para el sexo femenino. 